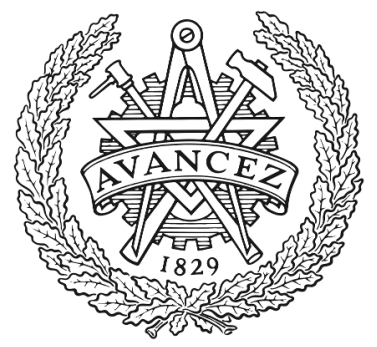

CHALMERS

UNIVERSITY OF TECHNOLOGY

\title{
Electrical resistivity measurements in steel fibre reinforced cementitious materials
}

Downloaded from: https://research.chalmers.se, 2023-04-26 12:04 UTC

Citation for the original published paper (version of record):

Berrocal, C., Hornbostel, K., Geiker, M. et al (2018). Electrical resistivity measurements in steel fibre reinforced cementitious materials. Cement and Concrete Composites, 89: 216-229.

http://dx.doi.org/10.1016/j.cemconcomp.2018.03.015

N.B. When citing this work, cite the original published paper. 


\title{
Electrical resistivity measurements in steel fibre reinforced cementitious materials
}

\author{
Carlos G. Berrocal ${ }^{* 1,3}$, Karla Hornbostel ${ }^{2,4}$, Mette. R. Geiker ${ }^{2}$, Ingemar Löfgren ${ }^{1,3}$, Karin Lundgren ${ }^{1}$, \\ Dimitrios G. Bekas ${ }^{5}$ \\ ${ }^{1}$ Chalmers University of Technology, Division of Structural Engineering, Sweden \\ ${ }^{2}$ Norwegian University of Science and Technology, Department of Structural Engineering, Norway \\ ${ }^{3}$ Thomas Concrete Group AB, Sweden \\ ${ }^{4}$ Norwegian Public Roads Administration, Norway \\ ${ }^{5}$ University of Ioannina, Department of Materials Science and Engineering, Greece \\ *Corresponding author; e-mail: carlos.gil@chalmers.se
}

\begin{abstract}
This paper reports results from experiments aimed at better understanding the influence of fibre dosage and fibre geometry on the AC frequency needed to determine the DC resistivity of cementitious materials containing steel fibres. Impedance spectroscopy and DC galvanodynamic measurements were performed on mortar prisms with varying fibre reinforcement to determine the matrix resistivity (related to ionic current within the pore solution) and composite resistivity (accounting for both ionic current and electronic current through the fibres). The results showed that adding steel fibres did not significantly affect the DC nor the AC matrix resistivity of the mortar prisms. However, the steel fibres yielded a drastic reduction of the frequency associated to the $\mathrm{AC}$ matrix resistivity from $\sim 1 \mathrm{kHz}$ in plain mortar to $\sim 1 \mathrm{~Hz}$ in steel fibre reinforced mortar. These findings revealed the need to adequately adjust the frequency in $\mathrm{AC}$ resistivity measurements of steel fibre reinforced cementitious materials.
\end{abstract}

Keywords: steel fibre reinforcement, cement-based materials, dielectric properties, impedance spectroscopy

\section{Introduction}

Fibre reinforcement has been successfully used to replace conventional reinforcement in various applications such as industrial floors and slabs on grade for crack control purposes, in precast tunnel lining segments to withstand the loads arising during the construction phase or as sprayed concrete for rock strengthening [1-3], with steel fibres being the most widely used fibre type. It has been shown that, in combination with traditional reinforcing bars, fibre reinforcement can provide crack control mechanisms that effectively control and reduce crack widths [4-6]. Consequently, using fibres could be beneficial also in other civil engineering structures to meet the crack width requirements specified in current structural codes $[7,8]$. Moreover, by limiting the crack width and changing the internal crack morphology, fibres have been found to decrease the permeation of cracked concrete and increase its self-healing capacity [9-12]. Therefore, fibre reinforcement could reduce the ingress of moisture and other detrimental agents into cracked concrete, e.g. $\mathrm{Cl}^{-}$, and thus potentially delay initiation of reinforcement corrosion in structures exposed to chloride environments $[13,14]$.

The resistivity of a material describes its ability to withstand the transfer of charge, which in plain concrete occurs as a current flow of electrically charged ions dissolved in the pore solution. Consequently, the resistivity of concrete can be used to indicatively describe the resistance to chloride ingress $[15,16]$ and the current flow between the anode and the cathode in reinforcement macro-cell corrosion $[17,18]$. For most exposure conditions, a correlation is observed whereby the corrosion rate in the reinforcement increases as the resistivity of the concrete decreases and, although resistivity alone may not be sufficient to assess the corrosion rate of reinforcement in concrete, as shown by the large 
scatter found in the literature [19], the resistivity of the concrete may still provide valuable information regarding the durability of the structure.

Over the past years, several studies investigating the durability of steel fibre reinforced concrete (SFRC) have reported that the addition of steel fibres to the concrete resulted in a significant decrease of the electrical resistivity when measured under alternating current (AC) at different fixed frequencies $[13,20$ 24]. Contrary to what it could be anticipated, experimental investigations on the influence of steel fibres on corrosion of conventional reinforcement revealed that in addition to a certain delay of corrosion initiation $[13,14,25]$, the corrosion rate of reinforcement, measured using polarisation techniques, was not affected by the incorporation of steel fibres [25-28]. The latter observation could be explained by the short length and disperse nature of the fibres throughout the concrete matrix, which would require the existence of an unrealistically high electric field to enable current conduction through them, as experimentally shown by Solgaard et al. [29].

The apparent contradiction among reported results of resistivity and corrosion rates in SFRC may arise from the measurement technique commonly used to assess the resistivity. AC measurements are generally preferred to assess the resistivity of cementitious materials in order to avoid errors induced by polarization of the electrodes or variation of the properties over time due to ion migration [30]. However, corrosion is an electrochemical process involving direct current (DC) and thus, the relevant parameter that needs to be assessed is the DC resistivity. For plain cementitious materials with high moisture contents, it has been shown that $\mathrm{AC}$ measurements at frequencies in the range of $100 \mathrm{~Hz}$ to $10 \mathrm{kHz}$ are suitable to accurately assess the DC electric resistivity [31]. However, in a recent investigation [32], it was observed that steel fibres significantly reduced the AC resistivity of concrete when measured under an excitation frequency of only $126 \mathrm{~Hz}$. This finding reveals that the frequency range considered suitable to determine the resistivity of plain cementitious materials might not be applicable to cement-based materials incorporating steel fibres.

Electrochemical Impedance Spectroscopy (EIS) is a technique used to measure the impedance of a system over a range of frequencies. EIS has been extensively used in the past to study the hardening process of cement as well as the dielectric properties of hardened cement-based materials [33-37]. In a Nyquist plot, $\left(-Z_{I m}\right.$ vs $\left.Z_{R e}\right)$, the impedance spectrum of plain cementitious materials is characterized by a single arc describing the material behaviour (material arc) and a spurious arc occurring at lower frequencies ascribed to polarization effects at the sample-electrode interface (electrode arc) [38], see Fig. 1. The value of the real impedance axis at the cusp between both arcs is regarded as the electric resistivity of the material, which is comparable to the resistivity measured under DC.

The incorporation of conductive fibres, e.g. steel or carbon fibres, into the matrix of a cementitious material at fibre dosages below the percolation threshold results in a notable change of the impedance spectrum, as reported in several studies [39-43]. When impedance data is presented in a Nyquist plot, the most apparent change attributable to the addition of conductive fibres is a subdivision of the material arc into two arcs (see Fig.1). This feature, sometimes referred to as 'dual-arc' [39], reveals that cementitious materials incorporating conductive fibres possess two characteristic points, the matrix resistance and the composite resistance, both of which describe the behaviour of the material at different frequency ranges. The matrix resistance, $R_{m-A C}$, represents the resistance to ionic current through the pore solution acting as electrolyte, which is the relevant parameter associated to the durability of the material (comparable to DC resistance, $R_{m-D C}$ ) and corresponds to the junction between the middle material arc and the rightmost spur resulting from polarization effects at the matrix-electrode interface. The composite resistance, $R_{c-A C}$, occurring at higher frequencies, corresponds to the cusp between the two material arcs and accounts for the combined transfer of ionic current through the electrolyte and electronic current through the conductive fibres [42]. Note that the subscripts $-{ }_{A C}$ and $-_{D C}$ will be consistently added hereafter to differentiate between measurements carried out under AC fields and under DC fields. 


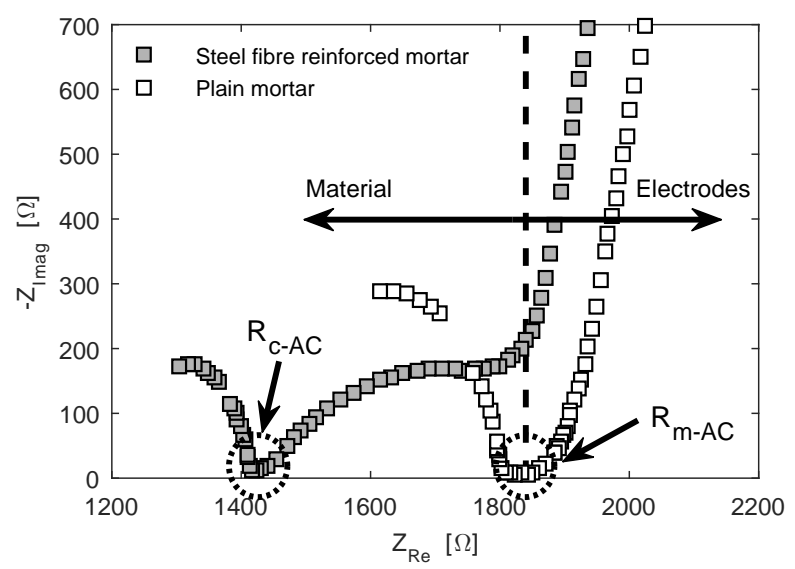

Figure 1. Impedance spectra for a plain mortar prism and a $0.5 \%$ vol. short steel fibre reinforced mortar prism, at 28 days of hydration. Indicated are the AC matrix resistivity, $R_{m-A C}$, related to ionic current within the pore solution, and the composite resistivity, $R_{c-A C}$, accounting for both the ionic flow and the electronic current through the fibres.

Most of the existing work involving EIS of cementitious materials containing conductive fibres aims at explaining the origin of dual-arc effect, which has been attributed to the high impedance of the passive layer formed on the surface of the steel fibres [39,42]. At low frequencies, the passive layer insulates the fibres whereas it becomes short-circuited at high frequencies thereby allowing current to flow through the fibres. The effect of varying the fibre length on the impedance of cementitious materials was investigated in [41], where a series of experiments combining EIS and four point DC measurements showed that the AC matrix resistivity of cementitious materials containing conductive fibres was in good agreement with the resistivity measured under DC. In a more recent study by Suryanto et al. [44], the authors showed that the mid-frequency arc of an engineered cementitious composite containing polyvinyl alcohol and steel fibres occurred at lower frequencies for increasing steel fibre contents. However, detailed information about the variation of the impedance response of cementitious materials due to the addition of conductive fibres in terms of the excitation frequency is very scarce and, particularly, the frequency needed to determine the AC matrix resistivity of cementitious materials with conductive fibres has not yet been specifically investigated.

In the present paper, EIS was employed to study the influence of the fibre length, fibre diameter and fibre dosage on the impedance response of specimens made of steel fibre reinforced mortar (SFRM). Complementary four-point DC galvanodynamic measurements were performed to determine the resistivity of the specimens under DC, which is the parameter indicative of the material durability. The results were combined to evaluate the frequency range needed to assess the $\mathrm{AC}$ matrix resistivity of steel fibre reinforced cement-based materials. Additionally, the impedance results were used to investigate the effect of the different steel fibre reinforcement features on the dielectric properties of SFRM, which might be of interest for a number of non-structural applications such as electromagnetic shielding or self-monitoring structures [45]. It should be noted that this investigation is limited to cases where fibres do not form a continuous electric path inside the matrix, i.e. where the fibre dosage is below the percolation threshold and the length of the fibres is shorter than the electrode separation.

\section{Description of experiments}

The experiments carried out within this study were aimed at investigating how varying the geometrical features and dosage of short steel fibres influenced the impedance response of SFRM samples in order to determine the frequency range for determination of the AC matrix resistivity.

The main parameters investigated in these experiments were: (i) the fibre dosage, including plain mortar $(0 \%$ vol.) and fibre reinforced mortar with fibre dosages below and near the percolation threshold $(0.5$ and $3.0 \%$ vol. respectively); (ii) the fibre length, including 6,12 and $25 \mathrm{~mm}$ long fibres; and (iii) the fibre diameter, with fibre diameters of $0.30,0.55$ and $0.92 \mathrm{~mm}$. Additionally, a series of specimens with 
polymeric fibres were cast to assess the impact of having an increased interface transition zone (ITZ) resulting from the addition of the (non-conducting) fibres. Three mortar specimens were prepared for each mix type investigated. The experimental programme is summarised in Tab. 1, where the nomenclature of the different mixes is introduced.

Table 1. Summary of experimental programme

\begin{tabular}{|c|c|c|c|c|c|c|}
\hline & & Fibre type & $\begin{array}{c}\text { Fibre } \\
\text { dosage } \\
{[\% \text { vol.] }}\end{array}$ & $\begin{array}{c}\text { Fibre length } \\
{[\mathrm{mm}]}\end{array}$ & $\begin{array}{c}\text { Fibre } \\
\text { diameter } \\
{[\mathrm{mm}]}\end{array}$ & $\begin{array}{c}\text { Mix } \\
\text { nomenclature }\end{array}$ \\
\hline \multirow{8}{*}{ 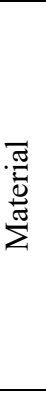 } & $\begin{array}{l}\text { Plain } \\
\text { mortar }\end{array}$ & - & $0 \%$ & - & - & $\mathrm{PM}$ \\
\hline & \multirow{7}{*}{ 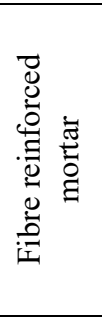 } & $\begin{array}{l}\text { Modified } \\
\text { olefin }\end{array}$ & $0.5 \%$ & 12 & $0.98^{a}$ & MO \\
\hline & & \multirow{6}{*}{$\begin{array}{c}\text { Low } \\
\text { carbon } \\
\text { steel }\end{array}$} & \multirow{5}{*}{$0.5 \%$} & 6 & 0.55 & S-0.5-6-0.55 \\
\hline & & & & \multirow{3}{*}{12} & 0.30 & S-0.5-12-0.30 \\
\hline & & & & & 0.55 & S-0.5-12-0.55 \\
\hline & & & & & 0.92 & S-0.5-12-0.92 \\
\hline & & & & 25 & 0.55 & S-0.5-25-0.55 \\
\hline & & & $3.0 \%$ & 12 & 0.55 & S-3.0-12-0.55 \\
\hline
\end{tabular}

${ }^{a}$ Equivalent diameter based on the actual perimeter of the non-circular fibre cross-section.

\subsection{Materials}

A cement of class CEM I 42.5 from Norcem was used as a binder to cast the different mortar mixes with a constant water to cement ratio $(w / c)$ of 0.55 . Standardized quartz sand in accordance to EN-196-1 [46] with a maximum particle size of $2 \mathrm{~mm}$ was used as aggregates. End-hooked fibres, Dramix 65/35-BN, made of cold-drawn low-carbon steel wire and featuring a length of $35 \mathrm{~mm}$ and $0.55 \mathrm{~mm}$ diameter were cut into smaller segments to achieve 6,12 and $25 \mathrm{~mm}$ long fibres, respectively. Another type of commercial fibre, Dramix 65/60-BN and steel cord were also cut to $12 \mathrm{~mm}$ long segments to obtain the fibres with $0.92 \mathrm{~mm}$ and $0.30 \mathrm{~mm}$ diameter, respectively. As polymeric fibres, a commercially available type of modified olefin fibre named BarChip Shogun was used cut into $12 \mathrm{~mm}$ segments.

\subsection{Geometry, preparation and curing of specimens}

Standard size prisms of dimensions $40 \times 40 \times 160 \mathrm{~mm}^{3}$, used e.g. to characterize the flexural and compressive strength of cement according to EN-196-1 [46], were used as test specimens in the present study. Two rectangular pieces of titanium mesh with dimensions $40 \times 60 \times 0.7 \mathrm{~mm}^{3}$, made of titanium grade 1 , were cast in the mortar prisms at $20 \mathrm{~mm}$ distance from each end to act as embedded electrodes for the EIS measurements. Additionally, two copper wires were similarly cast in the prisms at $30 \mathrm{~mm}$ from each of the titanium electrodes, leaving $1 \mathrm{~cm}$ of wire exposed, in order to measure potentials during 4-point DC measurements. The specimen dimensions and electrode configuration are schematically presented in Fig. 2.

The mortar mixes were prepared in a planetary motion mixer with a capacity of 51 according to the indications provided in EN-196-1 [46]. First, the cement was poured into the bowl containing the water and the mixer was started at low speed (140 rpm rotation / $62 \mathrm{rpm}$ planetary motion). After $30 \mathrm{~s}$, the sand and subsequently the fibres were gradually incorporated into the bowl during the next $30 \mathrm{~s}$ followed by an additional $30 \mathrm{~s}$ of mixing at high speed ( $285 \mathrm{rpm}$ rotation / $125 \mathrm{rpm}$ planetary motion). Subsequently, the mixer was stopped for $90 \mathrm{~s}$ and started once more at high speed for $60 \mathrm{~s}$. Tab. 2 shows the mix compositions for the four different mixtures investigated. Note that fibres were incorporated into the mix design by replacing the equivalent volume of sand. 


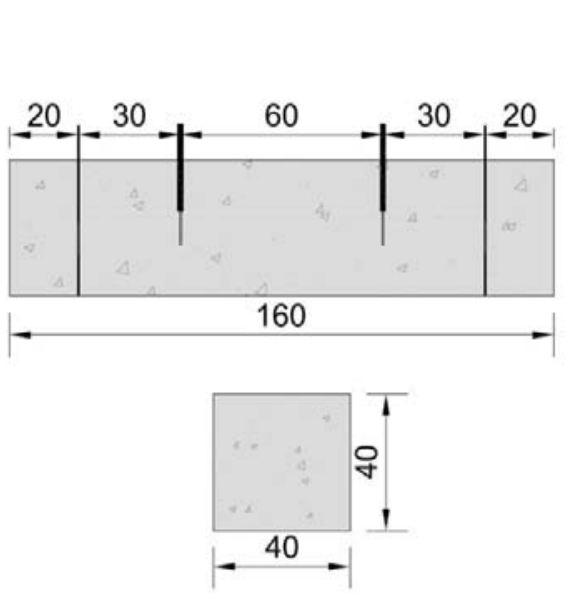

(a)

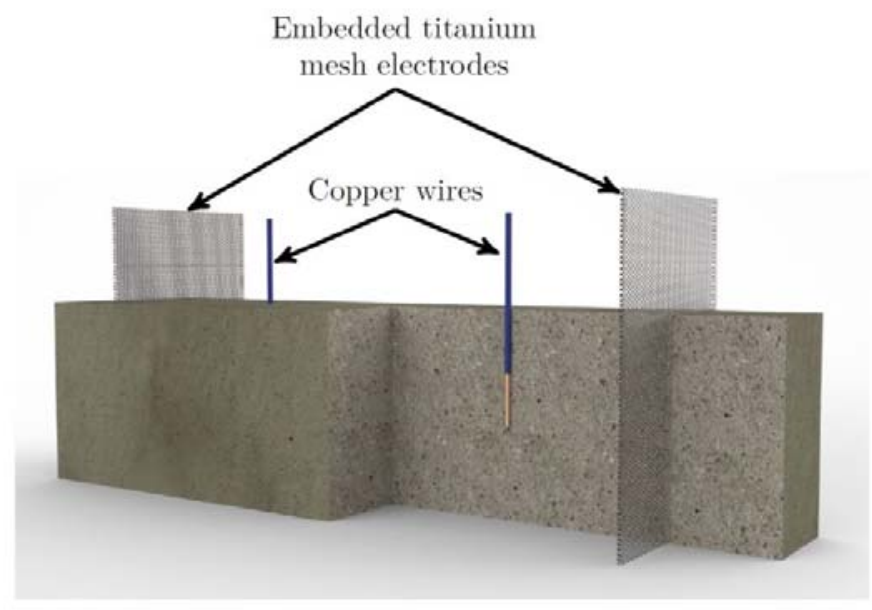

(b)

Figure 2. Specimen geometry (a) and 3D representation of specimen showing a cross-sectional cut to illustrate the position of the embedded electrodes (b). Measurements are in $\mathbf{m m}$.

Table 2. Mortar mix proportions, in $\left[\mathrm{kg} / \mathrm{m}^{3}\right]$

\begin{tabular}{lcccc}
\cline { 2 - 5 } & \multicolumn{4}{c}{ Fibre dosage [\% vol.] } \\
\cline { 2 - 5 } & $0 \%$ & $0.5 \%$ & $0.5 \%$ & $3.0 \%$ \\
\hline Cement & \multicolumn{4}{c}{473} \\
Water & 1502 & 1488 & 1488 & 1424 \\
Sand & - & Steel & Polyolefin & Steel \\
Fibre type & - & 39 & 4.56 & 234 \\
Fibre dosage & & \multicolumn{4}{c}{260} \\
\hline
\end{tabular}

After casting, all the prisms were left covered in the moulds to harden for a period of $24 \mathrm{~h}$ before demoulding. Subsequently, the specimens were wrapped in polyethylene sheets and placed in sealed containers partially filled with tap water to provide high relative humidity environment. At 7 days of hydration, the specimens were immersed in an alkaline solution containing $11.83 \mathrm{~g} / \mathrm{l}$ of KOH and 4.22 $\mathrm{g} / 1$ of $\mathrm{NaOH}(\mathrm{pH} \sim 13.5$ ) where they remained for the following 21 days. All the curing process was carried out in a temperature controlled room $\left(20 \pm 1^{\circ} \mathrm{C}\right)$.

\subsection{Measurement equipment and test procedures}

All the electrical measurements carried out in the present work were performed using a potentiostat of the type Princeton Applied Research PARSTAT 2273. The measurements on the mortar prisms were performed 28 days after casting. EIS measurements were performed prior to DC galvanodynamic measurements, leaving a $3 \mathrm{~h}$ time gap between measurements on the same specimen.

EIS measurements were carried out with a two-electrode configuration, with the working-electrode and reference-electrode leads connected to one of the titanium electrodes and the counter-electrode and sensing-electrode leads, to the other electrode. The frequency was swept from $1 \mathrm{MHz}$ down to $100 \mathrm{mHz}$, using a logarithmic point spacing at 30 points per decade and an $\mathrm{AC}$ amplitude of $500 \mathrm{mV}$ rms, a signal in the same order of magnitude as that of previous studies using this type of setup [39,44].

The DC galvanodynamic measurements were carried out using a four-electrode configuration, with the working-electrode and counter-electrode leads connected to the outer titanium electrodes and the 
reference-electrode and sensing-electrode leads, connected to the inner electrodes (copper wires). A current was generated at the outer electrodes, the magnitude of which was monotonically increased at a constant rate of $50 \mu \mathrm{A} / \mathrm{s}$, and the potential difference between the inner electrodes was continuously recorded, up to a maximum potential difference of $10 \mathrm{~V}$ limited by the capacity of equipment, in order to obtain the voltage-current curve of the specimen.

In all cases, prior to executing the electrical measurements, the open circuit potential was monitored and measurements were started when the observed potential drift was less than $0.1 \mathrm{mV} / \mathrm{s}$, thereby ensuring that the electrochemical cell was in equilibrium.

\section{Results and discussion}

\subsection{EIS measurement}

The results from the EIS measurements are presented in Fig. 3 for all the SFRM prisms at 28 days of hydration. In Fig. 3(a) the results are presented in the Nyquist plot format, i.e. the negative imaginary part of the impedance vs the real part of the impedance, whereas Fig. 3(b) displays the same results in the Bode plot format, i.e. phase angle vs excitation frequency. The EIS results are presented in a tabular format to provide an easier comparison of the effect of the different features investigated. The legend at the top-right corner indicates how the table should be read: the central row, from left to right, shows the effect of fibre length; the central column, from top to bottom, shows the effect of fibre diameter; the diagonal going from top-left to bottom-right shows the effect of fibre dosage; and finally, the bottomleft corner, which should be compared to the top-left corner, shows the potential effect of the cementfibre ITZ.

In every plot, three curves corresponding to the three specimens of each mix have been depicted to visualize the scatter in the measurements, which could be attributed to the existence of entrapped air or possible imperfections at the cement-electrode interface [37]. One of the curves is highlighted to indicate frequencies equal to the powers of 10. It must be noted that in order to show a clearer picture of the material arcs in Fig. 3(a), the scale of the y-axis has been varied between individual plots.

In all cases, the impedance response in the Nyquist plot format is characterized by a steep ascending branch visible at the right side of the plot, only partially shown in Fig. 3(a), which is associated to polarization effects at the cement matrix-electrode interface and would be part of a much larger arc occurring at the sub- $\mathrm{mHz}$ frequency range. At frequencies above $1 \mathrm{~Hz}$, specimens containing steel fibres exhibited a distinct response from PM and MO specimens. The latter two showed a single yet incomplete semi-circular material arc, indicating that frequencies in the $\mathrm{MHz}$ range are needed to observe a fully developed material arc [47]. The SFRM specimens, exhibited the expected dual-arc effect, in which the shape and size of the mid-frequency arc was clearly dependent on the fibre dosage and geometrical features of the fibres.

In the Bode plot format, Fig. 3(b), all the mixes are characterized by a very high phase angle at low frequencies below $1 \mathrm{~Hz}$ and a subtle increase of the phase angle for frequencies above $10^{5} \mathrm{~Hz}$. Additionally, a single peak of varying magnitude is apparent at intermediate frequencies for all the SFRM mixes. The phase angle describes the lag or delay between the applied electric field and the response of dipoles and charge carriers (ions and electrons) within the material. As the frequency increases, these are unable to simultaneously follow the variations of the external field due to friction and inertia effects thereby inducing hysteresis phenomena. In line with the observations from the Nyquist plots, the features observed in Fig. 3(b) in the low and high frequency range can be attributed to the relaxation of polarization processes at the electrode interface and bulk cement matrix, respectively. On the other hand, the single peak at intermediate frequencies is a feature attributable to interfacial polarization at the surface of the steel fibres, clearly influenced by the fibre dosage and geometrical features of the fibres. 

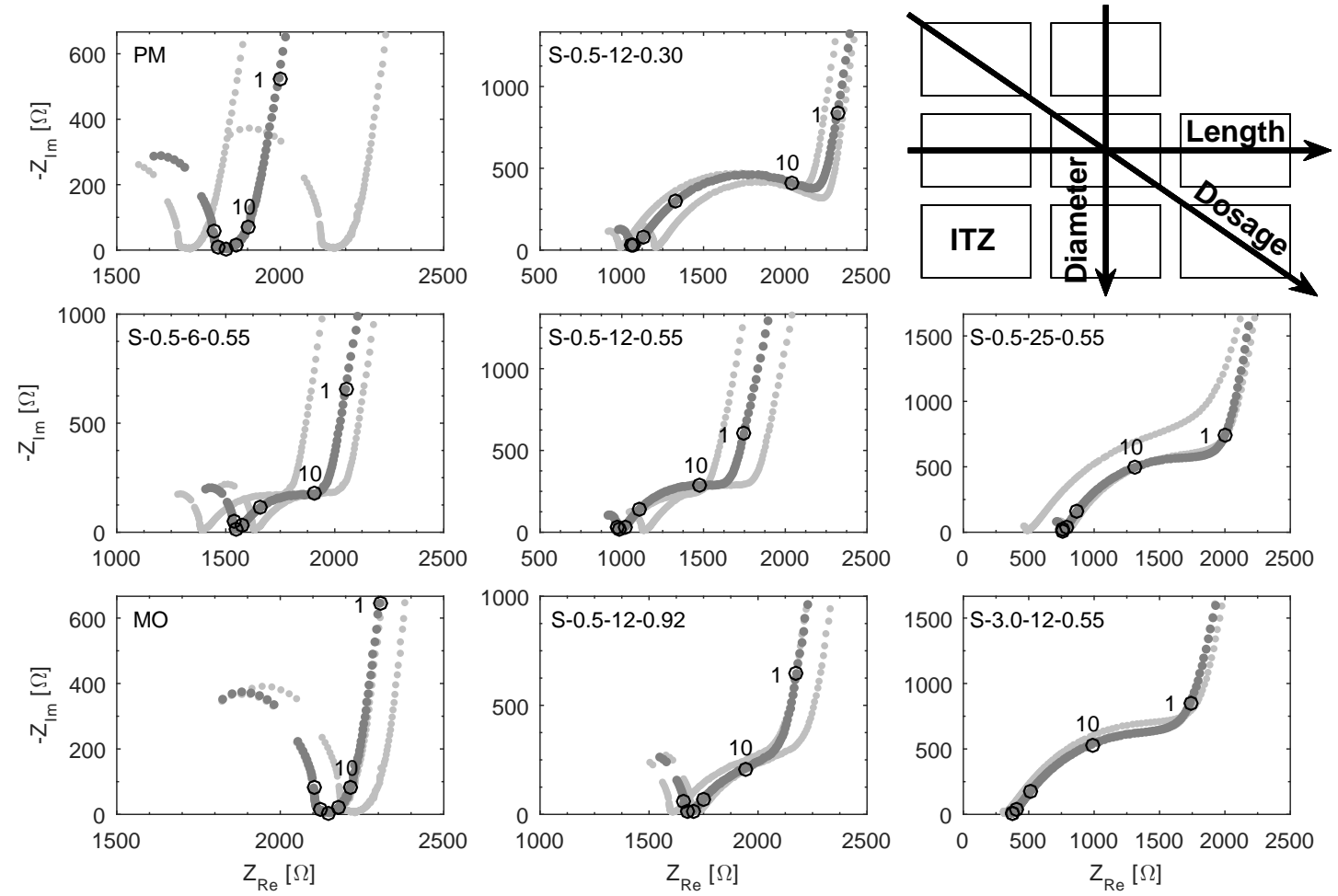

(a)
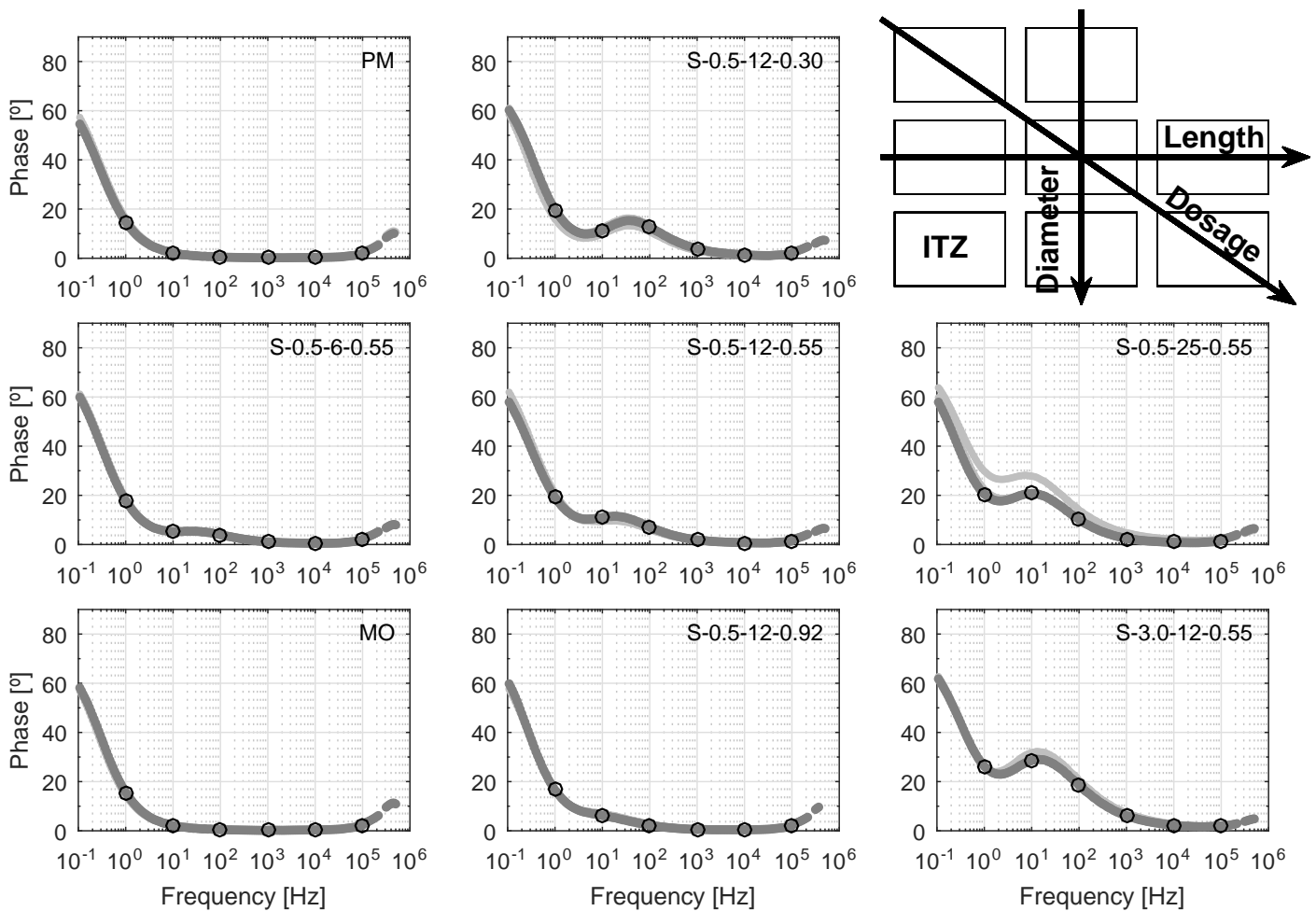

(b)

Figure 3. Nyquist plots (a) and Bode plots (b) for the different mixes at 28 days after casting. Three curves are presented in each plot to show the existing scatter between measurements performed on specimen of the same mix. Black hollow circles (highlighted on the dark curve) denote the excitation frequencies equal to the powers of 10, starting at $1 \mathrm{~Hz}$. Note that the scale of the $\mathrm{y}$-axis in (a) varies between plots. 
Another observable feature in Fig. 3(a) is the partial convolution between the mid-frequency arc in steel fibre reinforced samples and the electrode arc, which also seems dependent on the fibre geometry and fibre content. This feature has been attributed to the similarity between the time constants (or relaxation times) of the passive layer formed on the fibres and the double layer capacitance formed on the cementelectrode interface [48]. Unlike for PM and MO specimens, for which the matrix resistance can be directly determined from the measurements, the mid-frequency and electrode arcs in steel fibre reinforced specimens need to be de-convoluted in order to properly assess the matrix resistance.

The common procedure to perform the de-convolution of the two arcs consists in using an equivalent circuit and calibrate the circuit parameters to fit the experimental impedance data. In the literature, a large variety of equivalent circuits have been proposed to describe the frequency dependent electrical behaviour of cementitious materials, see e.g. [49-52], including a few for cementitious materials containing a conductive phase $[40,42,44,53]$.

The majority of proposed circuits assign different features based on the microstructure of cementitious materials (paste, pores, interfaces, etc.). However, the resulting parameters often lack a physical meaning or do not take into account the geometrical features of the conductive inclusions and their volume fraction. Furthermore, for a given impedance spectrum, multiple equivalent circuits may be found which are capable of successfully fit and reproduce the experimental data. Consequently, in this work, the equivalent circuit shown in Fig. 4(a), previously used by others [54], was employed.

As observed, the arcs displayed in Fig. 3(a) are not perfect semi-circles but instead have their centre slightly depressed below the $\mathrm{x}$-axis. This feature has been attributed to dielectric dispersion in the system, i.e. a superposition of relaxation processes taking place over a wide frequency range [44]. This effect can be modelled using a constant phase element (CPE) in parallel with a purely resistive element. The CPE is a complex circuit component with a frequency-dependent impedance that can be expressed as:

$$
Z_{C P E}(\omega)=\frac{1}{Q_{o}(j \omega)^{n}}
$$

where $j=\sqrt{ }-1, Q_{0}$ is a pseudo-capacitive coefficient, $\omega=2 \pi f$ is the angular frequency, being $f$ the excitation frequency, and $n$ can adopt values such that $0 \leq n \leq 1$, being $n=1$ equivalent to a perfect capacitor and $n=0$ equivalent to a perfect resistor. Fig. 4(b) illustrates a schematic representation of a possible impedance response of the equivalent circuit depicted in Fig. 4(a), in which the interpretation of each component contribution is shown.

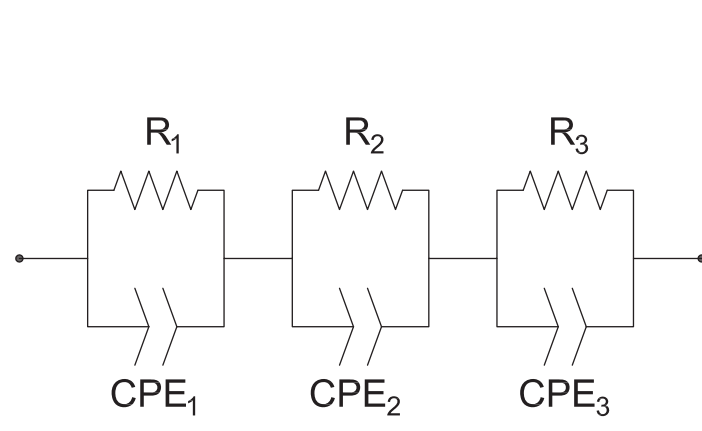

(a)

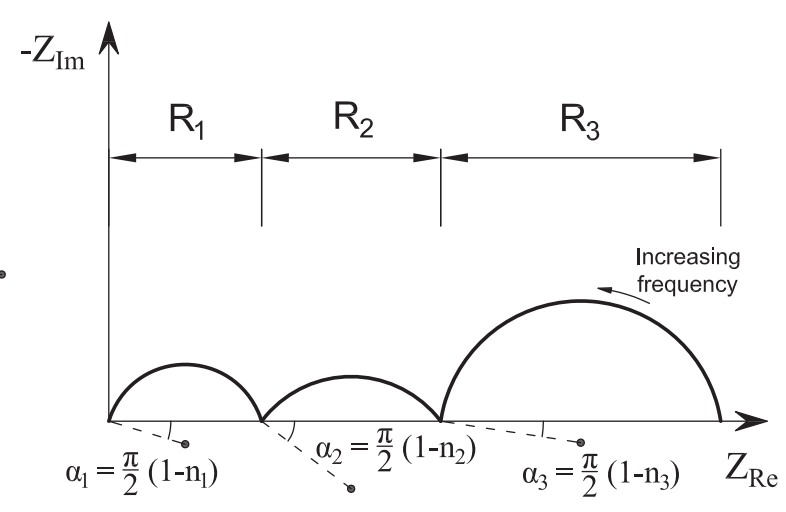

(b)

Figure 4. Equivalent circuit used to fit the impedance spectroscopy results (a) and interpretation of the circuit components (b).

Fig. 5 shows an example where the equivalent circuit presented in Fig. 4(a) has been fitted to the experimental impedance spectrum of a SFRM prism and the de-convoluted impedance response has been obtained. The AC matrix resistance, $R_{m-A C}$, is subsequently found as the intersection of the de- 
convoluted electrode arc (dashed line) with the real impedance axis, which is indicated in the Nyquist plot in Fig. 5(a). Its associated frequency, $f_{R_{m-A C}}$, hereafter referred to as the matrix frequency, is also indicated in the corresponding Bode plot in Fig. 5(b). The simulation parameters of the equivalent circuit for all the SFRM mixes are presented in Tab. 3.
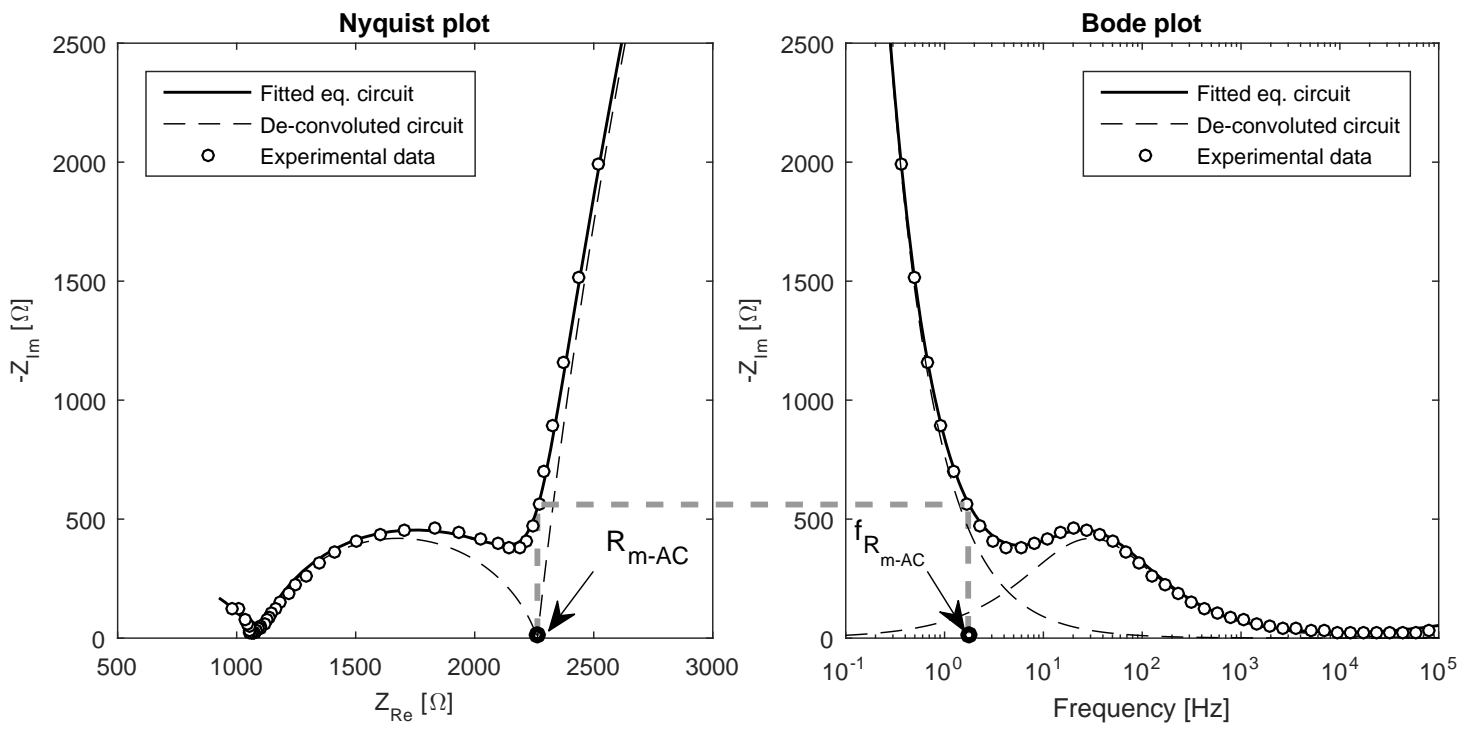

Figure 5. Example of experimental EIS response for mix S-0.5-12-0.30 (markers), the numerical simulation performed fitting the parameters of the circuit presented in Fig. 4. (solid line), and the de-convolution of the bulk and electrode arcs (dashed line). The matrix electrical resistance and the associated frequency are indicated.

Table 3. Fitting parameters of the equivalent circuit simulation for steel fibre reinforced prisms at 28 days of hydration

\begin{tabular}{|c|c|c|c|c|c|c|c|c|c|}
\hline & $\begin{array}{l}\mathrm{R}_{1} \\
{[\Omega]}\end{array}$ & $\begin{array}{c}\mathrm{Q}_{1} \\
{\left[\mathrm{~s}^{\mathrm{n} 1} \Omega^{-1}\right]}\end{array}$ & $\begin{array}{l}\mathrm{n}_{1} \\
{[-]}\end{array}$ & $\begin{array}{l}\mathrm{R}_{2} \\
{[\Omega]}\end{array}$ & $\begin{array}{c}\mathrm{Q}_{2} \\
{\left[\mathrm{~s}^{\mathrm{n} 2} \Omega^{-1}\right]}\end{array}$ & $\begin{array}{l}\mathrm{n}_{2} \\
{[-]}\end{array}$ & $\begin{array}{l}\mathrm{R}_{3} \\
{[\Omega]}\end{array}$ & $\begin{array}{c}\mathrm{Q}_{3} \\
{\left[\mathrm{~s}^{\mathrm{n} 3} \Omega^{-1}\right]}\end{array}$ & $\begin{array}{l}\mathrm{n}_{3} \\
{[-]}\end{array}$ \\
\hline \multirow{3}{*}{ S-0.5-6-0.55 } & 1399 & $6.96 \mathrm{E}-10$ & 0.80 & 429 & $4.49 \mathrm{E}-05$ & 0.73 & 100000 & $2.95 \mathrm{E}-04$ & 0.92 \\
\hline & 1560 & $3.40 \mathrm{E}-09$ & 0.69 & 437 & $5.41 \mathrm{E}-05$ & 0.71 & 79436 & $2.87 \mathrm{E}-04$ & 0.93 \\
\hline & 1639 & $1.35 \mathrm{E}-09$ & 0.75 & 440 & $4.96 \mathrm{E}-05$ & 0.72 & 80435 & $2.82 \mathrm{E}-04$ & 0.92 \\
\hline \multirow{3}{*}{ S-0.5-12-0.30 } & 1094 & $1.59 \mathrm{E}-08$ & 0.61 & 1169 & $1.33 \mathrm{E}-05$ & 0.79 & 67873 & $2.33 \mathrm{E}-04$ & 0.93 \\
\hline & 1015 & $1.01 \mathrm{E}-08$ & 0.64 & 1178 & $1.37 \mathrm{E}-05$ & 0.80 & 76240 & $2.41 \mathrm{E}-04$ & 0.94 \\
\hline & 1231 & $6.86 \mathrm{E}-09$ & 0.66 & 1073 & $1.43 \mathrm{E}-05$ & 0.80 & 88346 & $2.91 \mathrm{E}-04$ & 0.94 \\
\hline \multirow{3}{*}{ S-0.5-12-0.55 } & 1001 & 5.89E-09 & 0.67 & 691 & $3.79 \mathrm{E}-05$ & 0.76 & 91712 & $3.45 \mathrm{E}-04$ & 0.90 \\
\hline & 1151 & 4.09E-09 & 0.69 & 696 & $3.63 \mathrm{E}-05$ & 0.76 & 74624 & $3.12 \mathrm{E}-04$ & 0.91 \\
\hline & 1004 & 2.78E-09 & 0.72 & 581 & $5.82 \mathrm{E}-05$ & 0.71 & 99797 & $3.30 \mathrm{E}-04$ & 0.92 \\
\hline \multirow{3}{*}{ S-0.5-12-0.92 } & 1721 & $1.80 \mathrm{E}-09$ & 0.73 & 550 & $9.43 \mathrm{E}-05$ & 0.69 & 83620 & $2.90 \mathrm{E}-04$ & 0.93 \\
\hline & 1615 & $7.54 \mathrm{E}-10$ & 0.79 & 555 & $9.61 \mathrm{E}-05$ & 0.69 & 78178 & $3.10 \mathrm{E}-04$ & 0.94 \\
\hline & 1688 & $1.47 \mathrm{E}-09$ & 0.75 & 499 & $1.16 \mathrm{E}-04$ & 0.69 & 76893 & $2.96 \mathrm{E}-04$ & 0.95 \\
\hline \multirow{3}{*}{ S-0.5-25-0.55 } & 773 & 7.63E-09 & 0.67 & 1313 & 4.13E-05 & 0.76 & 107194 & $3.34 \mathrm{E}-04$ & 0.94 \\
\hline & 810 & $3.21 \mathrm{E}-08$ & 0.58 & 1320 & $4.25 \mathrm{E}-05$ & 0.75 & 89908 & $2.82 \mathrm{E}-04$ & 0.93 \\
\hline & 513 & $1.79 \mathrm{E}-07$ & 0.50 & 1763 & 5.91E-05 & 0.69 & 57755 & $2.28 \mathrm{E}-04$ & 0.97 \\
\hline \multirow{3}{*}{ S-3.0-12-0.55 } & 385 & $2.41 \mathrm{E}-07$ & 0.50 & 1491 & $3.97 \mathrm{E}-05$ & 0.74 & 64947 & $2.86 \mathrm{E}-04$ & 0.95 \\
\hline & 394 & $2.28 \mathrm{E}-07$ & 0.50 & 1454 & $4.24 \mathrm{E}-05$ & 0.73 & 81480 & $2.93 \mathrm{E}-04$ & 0.93 \\
\hline & 340 & $3.12 \mathrm{E}-07$ & 0.50 & 1630 & 4.11E-05 & 0.74 & 85322 & $2.97 \mathrm{E}-04$ & 0.95 \\
\hline
\end{tabular}




\subsection{DC galvanodynamic measurements}

In Fig. 6, the current-voltage relationship obtained from the four-point DC galvanodynamic measurements is presented for prisms belonging to two different mixes, namely PM and S-0.5-25-0.55. As observed in Fig. 6(a), for the PM prism the current-voltage relationship exhibited linearity, indicating the mortar behaved as an ideal resistor for the voltage range investigated. The DC matrix resistance could be therefore directly obtained by calculating the slope determined by the current-voltage relationship, as illustrated. Similarly, all the fibre reinforced mixes exhibited a linear current-voltage relationship within the range tested (up to $10 \mathrm{~V}$ ) with the exception of S-0.5-25-0.55, the response of which is illustrated in Fig. 6(b). This mix, containing the longest fibre length investigated, displayed a linear trend for potentials of up to $5 \mathrm{~V}$ (electric field $\sim 5 / 0.06=80 \mathrm{~V} / \mathrm{m}$ ) and a gradual loss of electrical resistance thereafter. In that case, the DC matrix resistance could be obtained by calculating the slope of the current-voltage relationship in the low voltage range, as illustrated in Fig. 6(b). Note that by using the four-electrode configuration, the polarization effects arising from electrochemical reactions occurring at the electrodes could be minimized in all cases, which is manifested in Fig. 6 as a nearly null potential value in the absence of externally applied current [31].

(a) PM

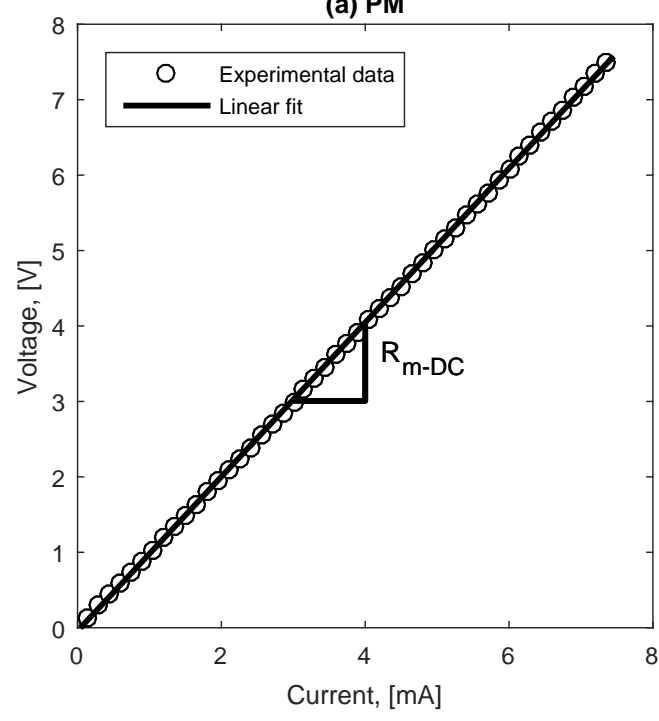

(b) S-0.5-25-0.55

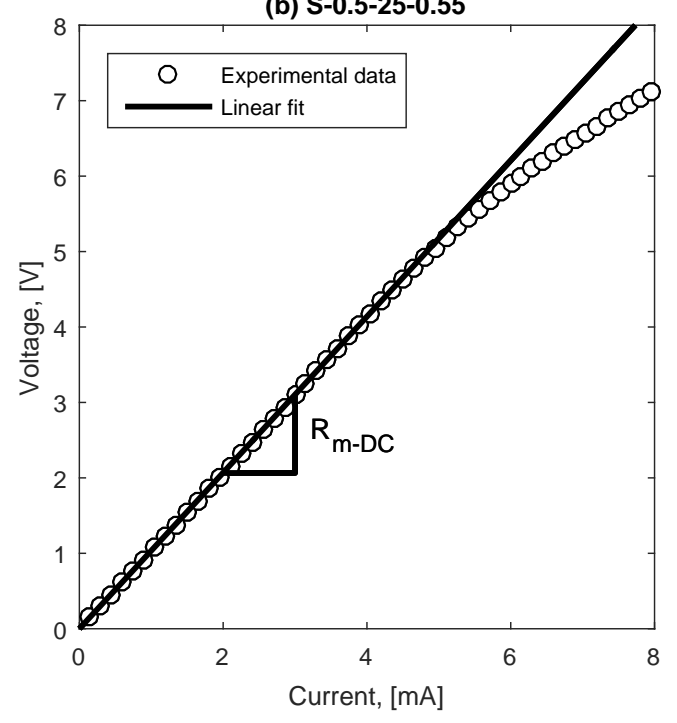

Figure 6. Experimental data from four-point DC galvanodynamic measurements performed on (a) a plain mortar prism and (b) a S-0.5-25-055 prism at 28 days hydration. A linear fit was used to find the DC matrix resistance of the mortar specimens.

As mentioned earlier, it had been previously found that steel fibres in concrete may act conductive in the presence of DC fields provided the field intensity is sufficiently strong (ca. $15 \mathrm{~V} / \mathrm{m}$ for a $35 \mathrm{~mm}$ long fibre aligned with the direction of the electric field [29]). Furthermore, the critical electric field intensity needed to obtain current conduction through the fibres has been observed to decrease with increasing fibre lengths [43]. These observations, supported by the findings presented in Fig. 6, explain why only the mix containing the longest fibres displayed a non-linear current-voltage relationship in the voltage range applied.

This observation might have some important implications in the applicability of test methods based on resistivity measurements, such as those used for determination of resistance to chloride ingress, e.g. NT Build 492 [55], ASTM C1202 [56], where usual values of the applied electric field reach $600 \mathrm{~V} / \mathrm{m}$ and $1200 \mathrm{~V} / \mathrm{m}$, respectively. In such cases, careful interpretation of the results is required as the measured current transfer will not only account for the ionic current through the pore network. Additionally, the existence of a critical electric field below which the fibres do not pick up current and the limited potential gradients developed in a corrosion macro-cell, hence limited electric fields, suggest that steel fibres are unlikely to contribute to the current flow in a corrosion macro-cell. Consequently, steel fibres are not expected to affect the corrosion rate of rebar in RC structures. 


\subsection{AC vs DC matrix resistivity}

Using the values of the AC and DC matrix resistances, obtained from the EIS and DC galvanodynamic measurements, respectively, the corresponding matrix resistivity, $\rho_{m}$ was calculated according to Eq. (2):

$$
\rho_{m}=R_{m} \cdot k
$$

where $R_{m}$ is the matrix resistance (either AC or DC) and $k=A / L$ is the cell constant, where $A$ is the prism cross-sectional area $\left(1600 \mathrm{~mm}^{2}\right)$ and $L$ is the inter-electrode distance, which was approximately $120 \mathrm{~mm}$ and $60 \mathrm{~mm}$ for EIS and DC measurements, respectively. Note that the exact position of the electrodes varied slightly between specimens and consequently the value of $L$ used to compute the cell constant $k$ was the actual inter-electrode measured distance. A comparison of the AC matrix resistivity and DC matrix resistivity, correspondingly denoted as $\rho_{m-A C}$ and $\rho_{m-D C}$, is presented in Fig. 7.

The calculated values of the AC matrix resistivity were in good agreement with the corresponding values of the DC matrix resistivity, although in average terms the former were found to be about $8 \%$ higher, as indicated in Fig. 7 by a thick dashed line. The results also showed a certain dispersion, most values being found within a deviation of $\pm 10 \%$ and a maximum deviation of up to $\pm 20 \%$. The dispersion shown in Fig. 7 was within the expected variation. According to technical recommendations by RILEM TC 154 [30], a coefficient of variation of $20 \%$ must be considered normal for resistivity measurements on laboratory specimens from the same mix and exposed identically.

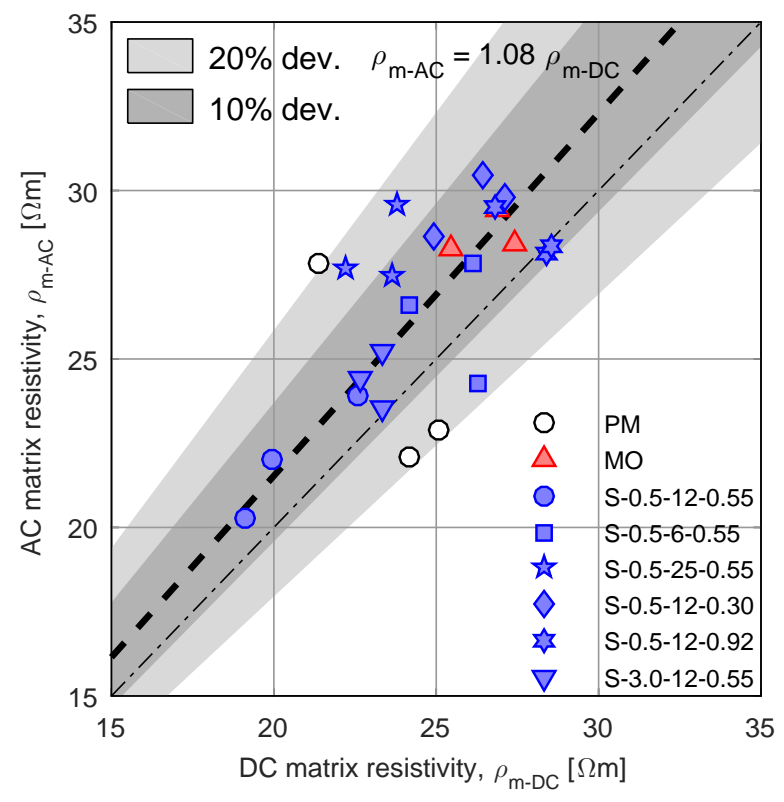

Figure 7. Comparison of the AC matrix resistivity of the mortar prisms determined from EIS measurements, $\rho_{m-A C}$, and DC matrix resistivity determined from DC galvanodynamic measurements, $\rho_{m}$ $D C$, according to Eq. (2) for all the mixes at 28 days hydration.

\subsection{Frequency dependence of the AC matrix resistivity}

The average AC matrix resistivity of all the mixes obtained from the EIS measurements, $\rho_{m-A C}$, is presented in Fig. 8 together with their associated AC frequency. It is apparent that the addition of fibres, either steel or polymeric, did not cause a significant change to the $\mathrm{AC}$ matrix resistivity compared to plain mortar, particularly considering the scatter observed for the PM mix. Moreover, no trend could be identified between the AC matrix resistivity and the fibre dosage or fibre features investigated. These observations indicate that neither the presence of the cement-fibre ITZ (cf. PM and MO mix) nor the 
steel fibres themselves, regardless of fibre dosage and fibre geometry employed, had an influence on the AC matrix resistivity of cementitious materials.

Regarding the $\mathrm{AC}$ frequency, adding polymeric fibres had no effect compared to plain mortar specimens as the frequency associated to the $\mathrm{AC}$ matrix resistance, $\sim 1 \mathrm{kHz}$ in this case, was the same for both mixes. Steel fibres, on the other hand, had a remarkable impact on the associated AC matrix frequency, which was reduced by three orders of magnitude regardless of the fibre dosage or fibre geometry, to ca. 0.5 to $2.5 \mathrm{~Hz}$. As a matter of fact, a trend could be observed for which longer fibres and higher fibre dosages, yielded a lower matrix frequency, whereas the effect of the fibre diameter was less apparent. Nevertheless, the changes in the matrix frequency observed for different fibre features were negligible compared to the difference between plain mortar and SFRM.

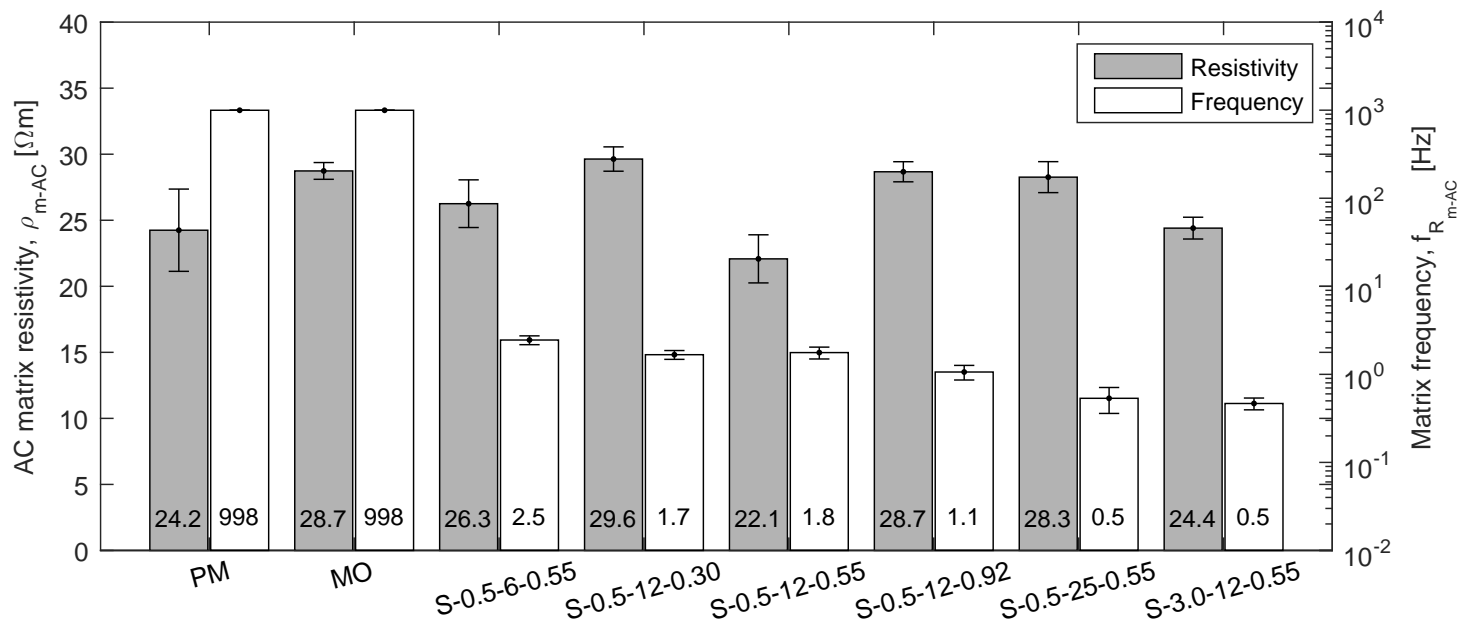

Figure 8. AC matrix resistivity of mortar prisms determined from EIS measurements, $\rho_{m-A C}$, and the associated AC matrix frequency, $f_{\mathrm{R}_{\mathrm{m}-\mathrm{AC}}}$, for all the mixes at 28 days hydration.

\subsection{Dielectric properties of SFRM}

In Fig. 9, various results extracted from the EIS measurements of the PM and SFRM specimens have been grouped to better illustrate the effect of the different features on the dielectric properties of SFRM. The results presented in Fig. 9 correspond to the specimens represented in Fig. 3 with a darker line. 

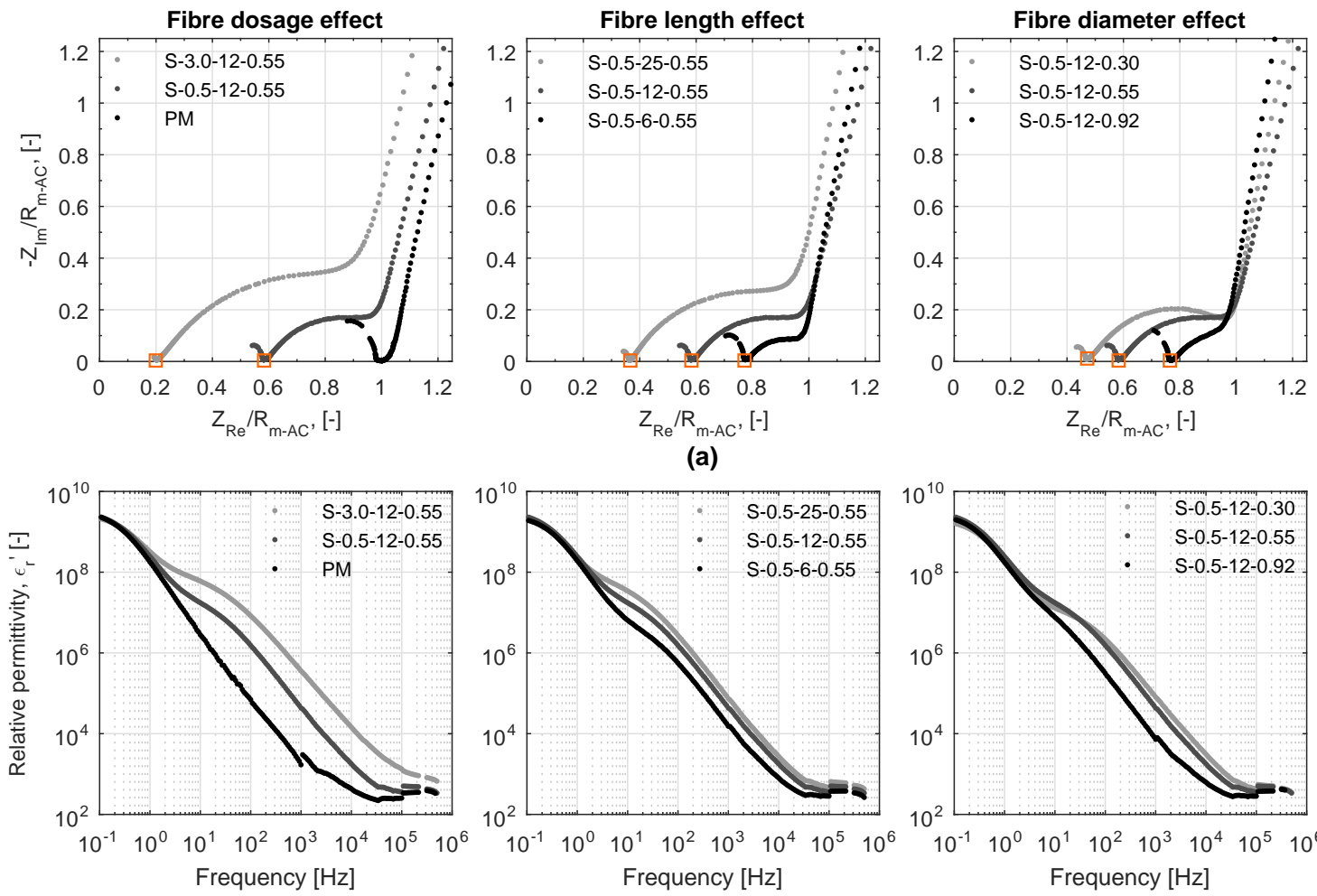

(a)
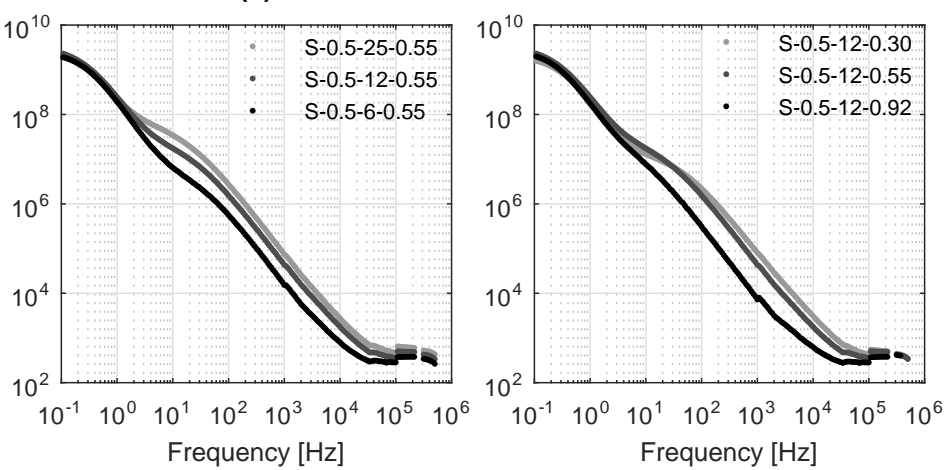

(b)
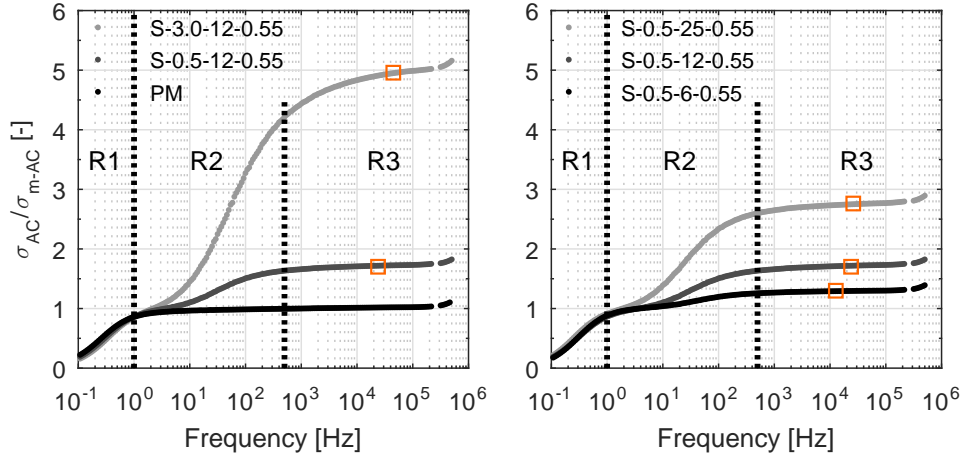

(c)

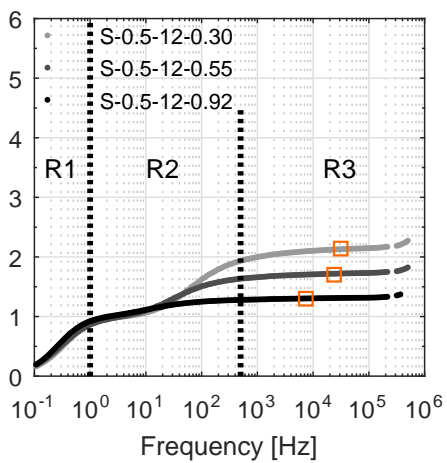

Figure 9. Nyquist plot normalized to the AC matrix resistance (a), variation of the relative permittivity (b) and AC conductivity (c) in the frequency domain. Square markers indicate the composite resistance/conductivity.

Fig. 9(a) presents the impedance results of the different mixes in Nyquist plots, where the real and imaginary parts of the impedance have been normalized to the AC matrix resistance of each mix. Thus, variations in the impedance response due to the contribution of the fibres can be more easily identified. As observed, increasing either the fibre dosage or the fibre length led to a significant increase of the size of the mid-frequency arc and a reduction of the high-frequency arc, whereas increasing the fibre diameter had the opposite effect, although to a lesser extent. The increase of the mid-frequency arc resulted in the displacement of the AC composite resistance point towards the axis origin, highlighted by red square markers in Fig. 9(a), indicating an overall reduction of the composite resistivity at high frequencies. The resulting AC composite resistance was as low as $20 \%$ of the AC matrix resistance for the mix containing 3\% vol. of steel fibres and about $40 \%$ for the mix with $25 \mathrm{~mm}$ long fibres.

It is interesting to note that for the mixes with increasing fibre dosage and varying fibre length, the cusp point between the mid-frequency and electrode arcs was progressively moved away from the real 
impedance axis as the size of the mid-frequency arc increased, thereby maintaining a similar shape of the impedance spectrum. However, in the case of the mixes with a varying fibre diameter, that point was not notably affected, resulting in a clear modification of the impedance spectrum shape and an apparent change in the degree of convolution between the mid-frequency and electrode arc. In particular, for the larger diameter investigated, the mid-frequency and electrode arcs were notably convoluted, making it more difficult to identify the cusp point between them.

Impedance is only one of the available quantities used to describe the electrical response of a system to an external alternating field. Grouped under the broader term immittance spectroscopy, other measured or derived quantities exist, related to the impedance, which can provide additional information regarding the processes occurring in the system [57]. One of these quantities is the relative permittivity, which can be expressed as a function of the impedance as [58]:

$$
\varepsilon_{r}(\omega)=\varepsilon_{r}{ }^{\prime}(\omega)-j \varepsilon_{r}^{\prime \prime}(\omega)=\frac{1}{j \varepsilon_{0} \omega Z(\omega)} \frac{L}{A}
$$

where $\varepsilon_{r}^{\prime}(\omega)$ and $\varepsilon_{r}^{\prime \prime}(\omega)$ are the real and imaginary parts of the relative permittivity, $\varepsilon_{0}=8.854 \times 10^{-12} \mathrm{~F} / \mathrm{m}$ is the permittivity of free space, $L$ and $A$ are the inter-electrode distance and the electrode area, respectively, and $\omega$ is the angular frequency as previously defined. The real part of the relative permittivity, sometimes called dielectric constant, describes the ability of the material to store electric energy due to polarization processes, i.e. due to the shift of electrically charged dipoles from their equilibrium position. The imaginary part of the relative permittivity accounts for the loss or dissipation of energy, including both relaxation of polarization processes and transfer of free charges (ions and electrons) through the material. Accordingly, the imaginary part of the relative permittivity can be expressed in terms of the conductivity, $\sigma(\omega)$, as:

$$
\varepsilon_{r}{ }^{\prime \prime}(\omega)=\frac{\sigma(\omega)}{\omega \varepsilon_{0}}
$$

Developing the right part of Eq. (3) and combining it with Eq. (4), the real part of the relative permittivity (relative permittivity for short, hereafter) and the conductivity can be de-embedded from the impedance as follows:

$$
\begin{aligned}
& \varepsilon_{r}{ }^{\prime}(\omega)=\frac{1}{\omega \varepsilon_{0}} \frac{Z_{I m}(\omega)}{|Z(\omega)|^{2}} \frac{L}{A} \\
& \sigma(\omega)=\frac{Z_{R e}(\omega)}{|Z(\omega)|^{2}} \frac{L}{A}
\end{aligned}
$$

where $|Z(\omega)|^{2}=Z_{R e}{ }^{2}+Z_{I m}{ }^{2}$, is the square of the impedance modulus. The variation of the relative permittivity and relative AC conductivity in the frequency domain are presented in Fig. 9(b) and Fig. $9(\mathrm{c})$, respectively.

As observed, for plain mortar, the relative permittivity decreased throughout the entire frequency range. This behaviour has been attributed to a superposition of various double-layer polarization mechanisms occurring at the matrix-electrode interface and at the interfaces between the pore solution and the cement hydration products $[47,59]$. Similar to plain mortar, the relative permittivity of the mixes with steel fibres decreased across the entire frequency range. However, SFRM specimens exhibited a greater permittivity compared to plain mortar, particularly in the intermediate frequency range. The increase in permittivity attributable to the addition of steel fibres can be explained by a change in the current conduction mechanism within the specimen. As the current is transferred from the electrolyte in the pores to the steel fibres, charged ions can accumulate at the surface of the fibres resulting in the formation of a new double-layer polarization mechanisms at the electrolyte-fibre interface [44].

Regarding the influence of the fibre dosage, fibre length and fibre diameter, only slight variations could be observed in the relative permittivity. Increasing the fibre dosage to $3 \%$ vol. resulted in the most apparent increase, whereas varying the geometrical features of the fibre did not yield a significant change in dielectric dispersion. Since the polarization mechanism attributed to the fibres depends on the 
electrolyte-fibre interface area, an increase in permittivity would be expected when the total fibre surface area is increased. However, the net contribution of the fibres to the polarization mechanism depends on the angle formed between the fibre surface and the direction of the electric field [42]. Therefore, the orientation of the fibres might have also played an important role in the contribution of the fibres to the enhancement of the relative permittivity at intermediate frequencies.

A more noticeable effect of the different fibre features can be seen on the frequency dependent AC conductivity, which has been presented in Fig. 9(c) normalized to the AC matrix conductivity. The plots in Fig. 9(c) can be subdivided into three distinct frequency regions. Region $1(R l)$, occurring at frequencies below $1 \mathrm{~Hz}$, corresponds to the frequency range governed by polarization effects at the cement-electrode interface. Region $2(R 2)$, occurring in the $\sim 1 \mathrm{~Hz}-500 \mathrm{~Hz}$ range, is characterized by an abrupt increase of the conductivity of fibre reinforced specimens. Following the increase in conductivity, a relative stabilization is observed in region $3(R 3)$, occurring at higher frequencies.

Looking at the $\mathrm{AC}$ conductivity of the plain mortar mix, it can be seen that it remained nearly unaltered throughout the $1 \mathrm{~Hz}-100 \mathrm{kHz}$ frequency range and, consequently, plain mortar could be regarded as frequency-independent for the investigated frequency range. The SFRM behaved as plain mortar when subjected to a low-frequency field. However, the AC conductivity of the material gradually raised as the oscillation frequency increased across the frequency range defining region 2, showing a particularly sharp increase when the frequency of the external alternating field exceeded a value of ca. $10 \mathrm{~Hz}$. The frequency window comprising region 2 could be considered as a frequency transition where energy loss in the composite material occurs due to a combination of relaxation processes at the surface of steel fibres and current transfer through the fibres. This behaviour makes SFRM a frequency-dependent material, as opposed to plain mortar.

This observation has been attributed to the passive layer of steel fibres [39,42]: a very thin and dense oxide film that forms on the surface of carbon steel in highly alkaline environments such as the pore solution of cement-based materials and limits the current transfer between the base steel and the surrounding electrolyte [60]. As evidenced by the results, the mentioned passive layer can be shortcircuited when the frequency of the applied AC field is significantly increased beyond the matrix frequency. Moreover, the passive layer could potentially act as a dielectric material for the double-layer polarization mechanism previously discussed.

Examining the frequency-dependent behaviour of SFRM, it is interesting to note that, in general, the extent of region 2 did not seem to be dependent on the different fibre features, except for the mix S-3.012-0.55, which exhibited an increasing $\mathrm{AC}$ conductivity through the entire frequency range. Furthermore, it can be also observed that despite the large variation in the magnitude of the conductivity among the different mixes, the frequency corresponding to the $\mathrm{AC}$ composite resistance, $R_{c-A C}$, indicated by square markers in Fig. 9(c), was contained within one frequency decade $\left(\sim 7 \cdot 10^{3}-7 \cdot 10^{4} \mathrm{~Hz}\right)$.

In the light of these results, it should be emphasised that standard AC measurements commonly used to determine the (matrix) resistivity of plain concrete cannot be directly applied to steel fibre reinforced cementitious materials. Indeed, considering their frequency-dependent behaviour, AC measurements performed at a fixed frequency in the range $100-1000 \mathrm{~Hz}$ will lead to erroneous values of the AC matrix resistivity of SFRC. Based on the results from this study, the adequate AC frequency employed to determine the AC matrix resistivity should be in the range $0.5-2.5 \mathrm{~Hz}$. However, this statement assumes saturated concrete at room temperature $\left(\sim 20^{\circ} \mathrm{C}\right)$. Since the moisture content and temperature are factors influencing the impedance response of cementitious materials [61], the appropriate frequency for SFRM might thus also change with the exposure conditions.

\subsection{Analytical prediction of the AC composite conductivity}

In order to study the individual effect of the fibre dosage and fibre geometry on the AC composite conductivity, a two-phase model called the Equivalent Inclusion Method (EIM), based on Effective Medium Theory (EMT), was used. The model was originally developed by Eshelby [62] to study the elastic strain-stress field in composite materials with short misoriented fibres and adapted later by Hatta and Taya [63] to predict heat conduction in steady-state. More recently, others have also used the model to investigate the influence of steel fibres on the electric conduction phenomenon in cementitious 
materials $[32,44]$. The main advantage of the model, apart from its simplicity, is its capacity to account for the fibre geometry and the theoretical distribution of the fibre orientation angle within the matrix.

In the EIM, the geometry of the fibres, considered as spheroids, is accounted for through the $S_{\mathrm{ij}}$ tensor (see [63]), which only depends on the semi-axes of the spheroids. For the particular case of prolate spheroids, i.e. ellipsoids where one of the semi-axes is much greater than the other two, the $S_{\mathrm{ij}}$ can be written in terms of the fibre length, $L$, and diameter, $\varnothing$, as shown by Eq. (7) and Eq. (8):

$$
\begin{aligned}
& S_{11}=S_{22}=\frac{L \emptyset^{2}}{2\left(L^{2}-\emptyset^{2}\right)^{3 / 2}}\left[\frac{L}{\emptyset}\left(\frac{L^{2}}{\emptyset^{2}}-1\right)^{1 / 2}-\cosh ^{-1} \frac{L}{\emptyset}\right] \\
& S_{33}=1-2 S_{11}
\end{aligned}
$$

Three different distributions of the fibre orientation have been considered in the present study: (i) a uniform spatial distribution, where the fibres are 3D randomly distributed; (ii) a 3D cosine type distribution, in which a larger proportion of the fibres is aligned with the direction of the applied electric field; and (iii) a Dirac delta type distribution, in which all the fibres are aligned with the direction of the electric field. The first and last type represent the extreme cases of a misoriented short fibre composite whereas the second case is an intermediate case. For the distributions just mentioned, a close form can be obtained to calculate the effective conductivity of the composite, $\sigma_{c}[63]$ :

- 3D randomly distributed

$$
\sigma_{c}=\sigma_{m}\left(1-\frac{v\left(\sigma_{m}-\sigma_{f}\right)\left[\left(\sigma_{f}-\sigma_{m}\right)\left(2 S_{33}+S_{11}\right)+3 \sigma_{m}\right]}{3\left(\sigma_{f}-\sigma_{m}\right)^{2}(1-v) S_{11} S_{33}+\sigma_{m}\left(\sigma_{f}-\sigma_{m}\right) R+3 \sigma_{m}^{2}}\right)
$$

where $R=3\left(S_{11}+S_{33}\right)-v\left(2 S_{11}+S_{33}\right)$

- $3 \mathrm{D}$ cosine distribution

$$
\sigma_{c}=\sigma_{m}\left(1+\frac{v\left(\sigma_{f}-\sigma_{m}\right)\left[\left(\sigma_{f}-\sigma_{m}\right)\left(S_{11}+S_{33}\right)+2 \sigma_{m}\right]}{2\left(\sigma_{f}-\sigma_{m}\right)^{2}(1-v) S_{11} S_{33}+\sigma_{m}\left(\sigma_{f}-\sigma_{m}\right)(2-f)\left(S_{11}+S_{33}\right)+2 \sigma_{m}^{2}}\right)
$$

- Aligned distribution

$$
\sigma_{c}=\sigma_{m}\left(1+\frac{v\left(\sigma_{f}-\sigma_{m}\right)}{\left[\left(\sigma_{f}-\sigma_{m}\right)(1-v)\right] S_{33}+\sigma_{m}}\right)
$$

where $\sigma_{m}$ and $\sigma_{f}$ are the matrix and fibre conductivity, respectively, and $v$ is the fibre dosage expressed as a volume fraction. Since we were interested in studying the effect of the fibres on the relative increase in composite conductivity compared to the matrix conductivity, only the ratio $\sigma_{f} / \sigma_{m}$ was needed, which was taken as $10^{8}$, based on the conductivity of carbon steel [64].

The analytical predictions of the AC composite conductivity according to Eq. 9-11 are displayed in Fig.10, together with the experimentally measured values, for the varying fibre dosage, fibre length and fibre diameter, presented in terms of the composite to matrix conductivity ratio $\sigma_{c-A C} / \sigma_{m-A C}$. 

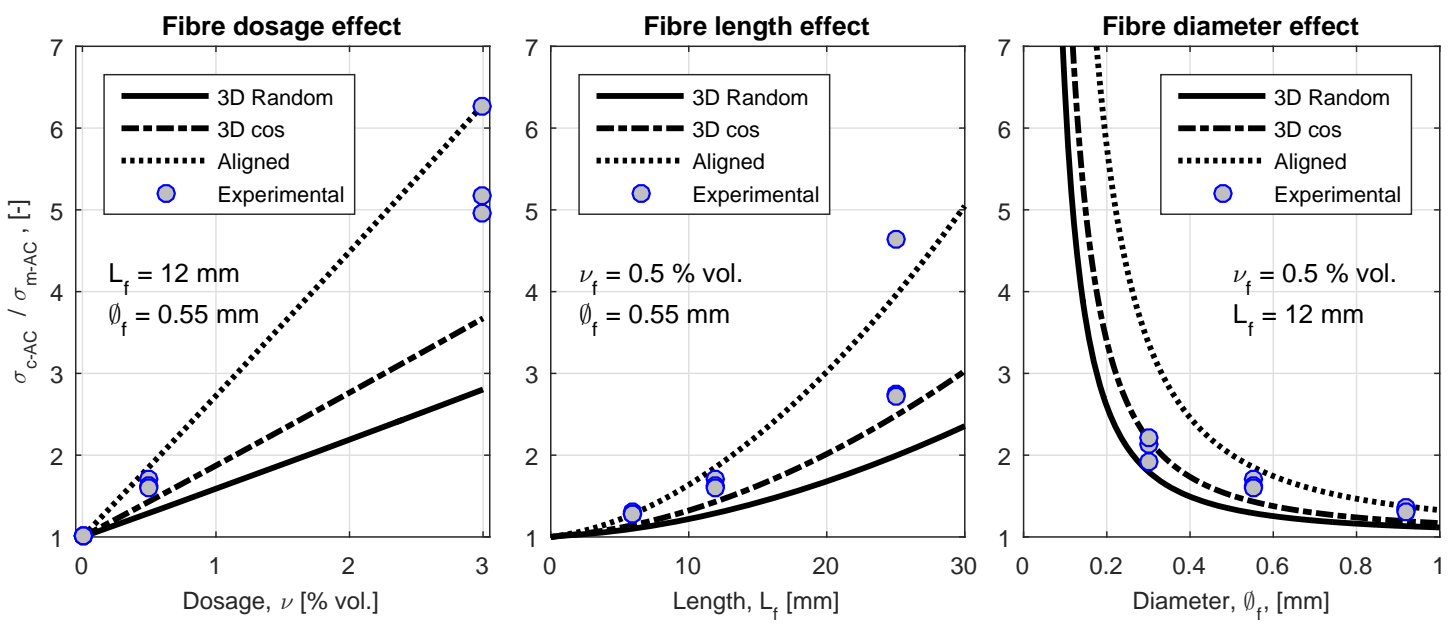

Figure 10. Experimentally measured values (circles) and simulated values by the EIM (lines) of the composite to matrix conductivity ratio for varying fibre dosage, fibre length and fibre diameter.

As observed in Fig. 10, there was a reasonable agreement between the model prediction and the experimental values, as the majority of these fell within the cases of $3 \mathrm{D}$ cosine and aligned fibre distribution. This would indicate that the fibres are not uniformly distributed throughout the matrix but a preferential alignment of the fibres with the direction of the external field exist. This preferential alignment can be explained by the small dimensions of the test specimens (relative to the fibre length) and the fact that the prisms were cast and not extracted from a larger element. Under these two circumstances, a certain wall-effect can be anticipated, where the fibres located near the side walls of the mould tend to be arranged parallel to the walls, thereby increasing the proportion of fibres aligned with the electric field.

On the other hand, the individual measured values of some mixes, such as S-3.0-12-0.55 with a fibre dosage of $3 \%$ vol. that should be near the percolation threshold or S- $0.5-25-0.55$ containing $25 \mathrm{~mm}$ long fibres, exhibited significantly higher AC conductivities close to or even beyond the perfectly aligned fibre distribution extreme case. One explanation to this observation could be attributed to the existence of electrical contacts between clusters of two or more adjacent fibres, which would increase the effective length of the fibre or contact between the fibres and the embedded electrodes.

Looking in detail on the effect of the different fibre features on the relative increase in conductivity predicted by the model, it is interesting to note that for the fibre dosages commonly used in fibre reinforced concrete applications, ranging from 0.5 to $1.5 \%$ vol., the $\mathrm{AC}$ composite conductivity increased proportionally to the fibre dosage. Since reaching the percolation threshold would require a higher dosage for most of the commercially available macro-fibres, it is concluded that in practice only a limited increase in $\mathrm{AC}$ conductivity might be expected by increasing the fibre dosage. However, the effect of increasing the fibre length and particularly the reduction of the fibre diameter, revealed a potential for substantially more AC conductive fibre reinforced composites. This can be attributed to the effect of the aspect ratio, which has been previously shown to have a significant impact on the AC resistivity of fibre reinforced concrete, see e.g. Solgaard et al. [32].

It should be noted, however, that the EIM does not take into consideration the possible interconnection of single fibres. According to Hatta and Taya [63], who carried out a sensitivity analysis of several parameters, the effect of the aspect ratio on the AC composite conductivity would be only noticeable up to values of about $L / \varnothing=50$. In their analysis, they used a volume fraction of $0.4(40 \%$ vol. dosage) and a fibre to matrix conductivity ratio of $\sigma_{f} / \sigma_{m}=20$. The results of their analysis are reproduced in Fig. 11(a), where the grey-shaded area represents the possible range of conductivity increase arising from the different fibre distributions between the two extreme cases. In the same plot, another analysis is included for a much lower volume fraction of only $0.02(2 \% \mathrm{vol}$.) to show the effect of the fibre dosage. In Fig. 11(b), the exact same analysis as in Fig. 11(a) is shown with the only difference of a change in 
the fibre to matrix conductivity ratio, which was increased up to $\sigma_{f} / \sigma_{m}=10^{8}$, the value adopted for the analyses shown in Fig. 10.

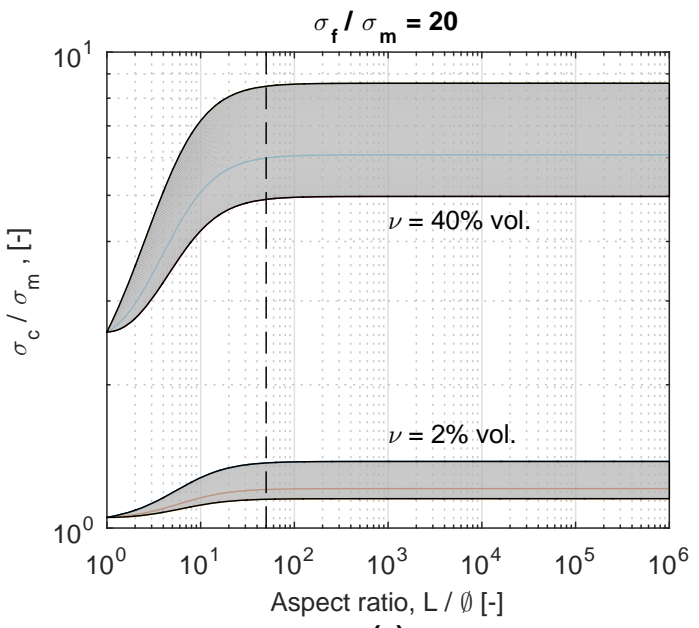

(a)

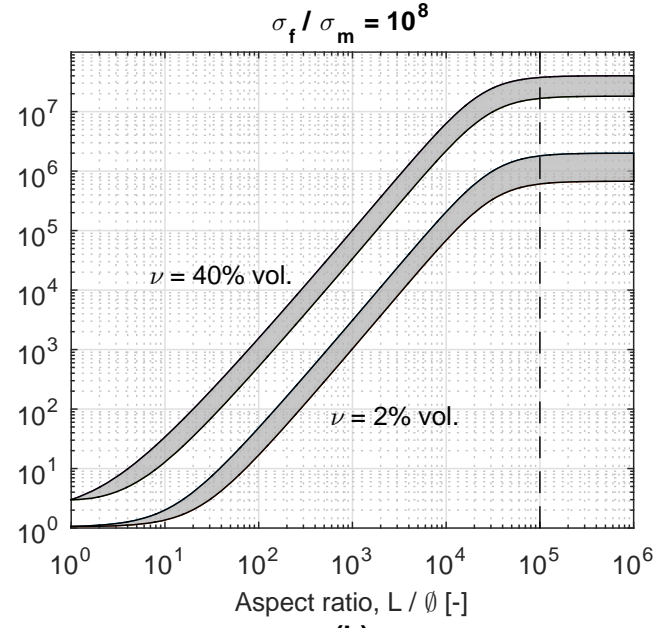

(b)

Figure 11. Effect of fibre dosage and fibre aspect ratio on the composite to matrix conductivity ratio according to the EIM for a fibre to matrix conductivity ratio of (a) 20 and (b) $10^{8}$. Grey shaded areas represent the potential fibre distributions between the extreme cases of $3 \mathrm{D}$ randomly oriented fibres and perfectly aligned fibres with the direction of the electric field.

As observed in Fig. 11(a), the AC composite conductivity does not significantly increase as the aspect ratio exceeds a value of about 50 and varying the fibre dosage did not have any effect on the critical aspect ratio. On the other hand, varying the $\sigma_{f} / \sigma_{m}$ had a notable impact on the critical aspect ratio, which increased up to a value of about $10^{5}$ but still with no influence of the fibre dosage, see Fig. 11(b). Since the percolation threshold in a fibre reinforced composite is a function of the aspect ratio, the critical aspect ratio should be influenced by the increase in fibre dosage. Moreover, for carbon fibres with aspect ratios in the range 100 to 1000 , reported values of the percolation threshold occur at significantly lower fibre dosage ( $0.25-2 \%$ vol.) [65]. Consequently, the EIM should be only used when the fibres are well dispersed in the matrix and with combinations of aspect ratio and fibre dosage below the percolation threshold.

\section{Conclusions}

Electrochemical impedance spectroscopy (EIS) measurements were carried out on plain mortar specimens and fibre reinforced mortar specimens with a frequency scan ranging from $100 \mathrm{mHz}$ to 1 $\mathrm{MHz}$. Various fibre features and fibre contents were investigated, limiting the fibre dosage to values below the percolation threshold and using a fibre length shorter than the electrode separation, so a continuous electric path would not be formed. The following conclusions were drawn:

1. The addition of steel fibres into mortar specimens modified their impedance response, which was manifested as a change in the Nyquist plot from single arc behaviour to dual-arc behaviour. Modified Olefin fibres, on the other hand, did not result in any apparent change of the impedance response. Unlike for plain mortar, the impedance response of SFRM specimens showed a partial convolution between the electrode and mid-frequency arcs. Consequently, in order to accurately determine the value of the AC matrix resistance, an equivalent circuit model was required to analyse the different impedance spectra.

2. The addition of steel fibres also modified the DC current-voltage behaviour provided a certain electric field strength dependent on the fibre length was exceeded, which in the present study was found to be ca. $80 \mathrm{~V} / \mathrm{m}$ for $25 \mathrm{~mm}$ long fibres. This raises questions regarding the applicability of certain test methods based on the electric resistivity of concrete to characterize the resistance to chloride ingress in SFRC. Furthermore, the relatively high electric fields 
needed for steel fibres to act conductive suggests that fibre reinforcement will likely not contribute to increase the corrosion rate in RC structures due to the limited electric fields produced by macro-cell corrosion.

3. A comparison of the results obtained from the EIS (AC) and DC galvanodynamic measurements of the different mortar specimens showed that neither the cement-fibre ITZ nor the steel fibres, irrespective of the fibre dosage, length or diameter investigated, had a significant effect on the AC matrix or DC resistivity, which is the parameter related to the transfer of ionic current through the pore solution and the relevant indicator of the concrete durability.

4. Despite no significant differences were observed between the AC matrix resistivity of plain and fibre reinforced mortars, the frequency associated to the AC matrix resistivity was greatly influenced by the presence of steel fibres, shifting from $\sim 1000 \mathrm{~Hz}$ for plain mortar to $\sim 1 \mathrm{~Hz}$ for steel fibre reinforced mortar. This finding reveals that $\mathrm{AC}$ resistivity measurements on steel fibre reinforced cementitious materials need to be adequately adjusted if the matrix resistivity of the material should be determined.

5. In the frequency domain, steel fibres had the largest impact on the impedance response at intermediate frequencies $(\sim 10 \mathrm{~Hz}$ to $50 \mathrm{kHz})$. This was shown by the increased relative permittivity and the development of the mid-frequency arc, clearly dependent on the fibre dosage and fibre geometry. In terms of the AC conductivity, the response of plain mortar specimens was found to be practically independent of the frequency. On the other hand, the conductivity of SFRM specimens was highly dependent on the frequency, exhibiting a response which could be divided into three regions corresponding to an electrode polarization effect region, a transition frequency region and a stabilization region.

6. Analytical predictions according to the Equivalent Inclusion Method showed a reasonable agreement with the experimentally measured values of the AC composite conductivity. The results of the model indicate that fibres likely had a preferential orientation, which was attributed to the wall-effect. Moreover, at low fibre dosages, the AC composite conductivity increased linearly with the fibre dosage, whereas increasing the aspect ratio of the fibres resulted in a greater conductivity of the composite. However, it was found that the model is only applicable when the fibre dosage is below the percolation threshold.

\section{Acknowledgements}

The authors would like to acknowledge the funds received from Åke och Greta Lissheds Stiftelse.

\section{References}

[1] I. Löfgren, Fibre-reinforced concrete for industrial construction - a fracture mechanics approach to material testing and structural analysis, Chalmers University of Technology, 2005.

[2] E. Nordström, Durability of Sprayed Concrete Steel fibre corrosion in cracks, Luleå University of Technology, 2005.

[3] A. de la Fuente, P. Pujadas, A. Blanco, A. Aguado, Experiences in Barcelona with the use of fibres in segmental linings, Tunn. Undergr. Sp. Technol. 27 (2012) 60-71. doi:10.1016/j.tust.2011.07.001.

[4] H.H. Abrishami, D. Mitchell, Influence of steel fibers on tension stiffening, ACI Struct. J. 94 (1997) 769-776.

[5] K. Noghabai, Behavior of Tie Elements of Plain and Fibrous Concrete and Varying Cross Sections, ACI Struct. J. 97 (2000) 277-285. doi:10.14359/857.

[6] A. Jansson, M. Flansbjer, I. Löfgren, K. Lundgren, K. Gylltoft, Experimental investigation of surface crack initiation, propagation and tension stiffening in self-compacting steel-fibrereinforced concrete, Mater. Struct. 45 (2012) 1127-1143. doi:10.1617/s11527-012-9821-6.

[7] EN 1992-1-1 Eurocode 2, EN 1992-1-1 Eurocode 2: Design of concrete structures - Part 1-1: 
General rules and rules for buildings, (2004).

[8] ACI Committee 318, 318-11: Building Code Requirements for Structural Concrete and Commentary, (2011) 503.

[9] M. Tsukamoto, J.-D. Wörner, Permeability of Cracked Fibre-Reinforced Concrete, Darmstadt Concr. 6 (1991) 123-135.

[10] J.S. Lawler, D. Zampini, S.P. Shah, Permeability of Cracked Hybrid Fiber-Reinforced Mortar under Load, ACI Mater. J. 99 (2002) 379-385.

[11] J. Rapoport, C. Aldea, S.P. Shah, B. Ankenman, A. Karr, Permeability of Cracked Steel FiberReinforced Concrete, J. Mater. Civ. Eng. 14 (2002) 355-358. doi:10.1061/(ASCE)08991561(2002)14:4(355)

[12] C.G. Berrocal, I. Löfgren, K. Lundgren, N. Görander, C. Halldén, Characterisation of bending cracks in R/FRC using image analysis, Cem. Concr. Res. 90 (2016) 104-116. doi:10.1016/j.cemconres.2016.09.016.

[13] C.G. Berrocal, I. Löfgren, K. Lundgren, L. Tang, Corrosion initiation in cracked fibre reinforced concrete: Influence of crack width, fibre type and loading conditions, Corros. Sci. 98 (2015) 128139. doi:10.1016/j.corsci.2015.05.021.

[14] M. Sappakittipakorn, N. Banthia, Corrosion of Rebar and Role of Fiber Reinforced Concrete, J. Test. Eval. 40 (2012). doi:10.1520/JTE103873.

[15] R.B. Polder, W.H.. Peelen, Characterisation of chloride transport and reinforcement corrosion in concrete under cyclic wetting and drying by electrical resistivity, Cem. Concr. Compos. 24 (2002) 427-435. doi:10.1016/S0958-9465(01)00074-9.

[16] C. Andrade, R. D'Andrea, N. Rebolledo, Chloride ion penetration in concrete: The reaction factor in the electrical resistivity model, Cem. Concr. Compos. 47 (2014) 41-46. doi:10.1016/j.cemconcomp.2013.09.022.

[17] S. Feliu, J.A. González, S. Feliu, C. Andrade, Relationship between conductivity of concrete and corrosion of reinforcing bars, Br. Corros. J. 24 (1989) 195-198. doi:10.1179/000705989798270027.

[18] W. Morris, A. Vico, M. Vazquez, S.. de Sanchez, Corrosion of reinforcing steel evaluated by means of concrete resistivity measurements, Corros. Sci. 44 (2002) 81-99. doi:10.1016/S0010938X(01)00033-6.

[19] K. Hornbostel, C.K. Larsen, M.R. Geiker, Relationship between concrete resistivity and corrosion rate - A literature review, Cem. Concr. Compos. 39 (2013) 60-72. doi:10.1016/j.cemconcomp.2013.03.019.

[20] C. Tsai, L. Li, C. Chang, C. Hwang, Durability design and application of steel fiber reinforced concrete in Taiwan., Arab. J. Sci. Eng. 34 (2009) 57-79.

[21] C. Frazão, A. Camões, J. Barros, D. Gonçalves, Durability of steel fiber reinforced selfcompacting concrete, Constr. Build. Mater. $80 \quad$ (2015) 155-166. doi:10.1016/j.conbuildmat.2015.01.061.

[22] T.A. Söylev, T. Özturan, Durability, physical and mechanical properties of fiber-reinforced concretes at low-volume fraction, Constr. Build. Mater. 73 (2014) 67-75. doi:10.1016/j.conbuildmat.2014.09.058.

[23] M. Nili, V. Afroughsabet, Property assessment of steel-fibre reinforced concrete made with silica fume, Constr. Build. Mater. 28 (2012) 664-669. doi:10.1016/j.conbuildmat.2011.10.027.

[24] L. Fiala, J. Toman, J. Vodička, V. Ráček, Experimental Study on Electrical Properties of Steel- 
fibre Reinforced Concrete, Procedia Eng. $151 \quad$ (2016) 241-248. doi:10.1016/j.proeng.2016.07.362.

[25] J. Blunt, G. Jen, C.P. Ostertag, Enhancing corrosion resistance of reinforced concrete structures with hybrid fiber reinforced concrete, Corros. Sci. 92 (2015) 182-191. doi:10.1016/j.corsci.2014.12.003.

[26] J.A. Grubb, J. Blunt, C.P. Ostertag, T.M. Devine, Effect of steel microfibers on corrosion of steel reinforcing bars, Cem. Concr. Res. 37 (2007) 1115-1126. doi:10.1016/j.cemconres.2007.04.012.

[27] H. Mihashi, S.F.U. Ahmed, A. Kobayakawa, Influence of crack widths on corrosion of reinforcing steel bar in fiber reinforced cementitious composites, in: Int. RILEM Conf. Adv. Constr. Mater. Through Sci. Eng., Hong Kong, CHina, on 5-7 September, 2011: p. n/a.

[28] B. Kim, a. J. Boyd, J.-Y. Lee, Effect of transport properties of fiber types on steel reinforcement corrosion, J. Compos. Mater. 45 (2010) 949-959. doi:10.1177/0021998310380286.

[29] A.O.S. Solgaard, M. Carsana, M.R. Geiker, A. Küter, L. Bertolini, Experimental observations of stray current effects on steel fibres embedded in mortar, Corros. Sci. 74 (2013) 1-12. doi:10.1016/j.corsci.2013.03.014.

[30] R.B. Polder, Test methods for on site measurement of resistivity of concrete - a RILEM TC154 technical recommendation, Constr. Build. Mater. 15 (2001) 125-131. doi:10.1016/S09500618(00)00061-1.

[31] N. Banthia, S. Djeridane, M. Pigeon, Electrical Resistivity of Carbon and Steel micro-fiber reinforced cements, Cem. Concr. Res. 22 (1992) 804-814. doi:10.1016/0008-8846(92)90104-4.

[32] A.O.S. Solgaard, M. Geiker, C. Edvardsen, A. Küter, Observations on the electrical resistivity of steel fibre reinforced concrete, Mater. Struct. 47 (2014) 335-350. doi:10.1617/s11527-0130064-y.

[33] W.J. McCarter, S. Garvin, N. Bouzid, Impedance measurements on cement paste, J. Mater. Sci. Lett. 7 (1988) 1056-1057. doi:10.1007/BF00720825.

[34] W.J. McCarter, R. Brousseau, The A.C. response of hardened cement paste, Cem. Concr. Res. 20 (1990) 891-900. doi:10.1016/0008-8846(90)90051-X.

[35] P. Gu, Z. Xu, P. Xie, J.J. Beaudoin, Application of A.C. impedance techniques in studies of porous cementitious materials, Cem. Concr. Res. 23 (1993) 531-540. doi:10.1016/00088846(93)90003-R.

[36] C.A. Scuderi, T.O. Mason, H.M.M. Jennings, Impedance spectra of hydrating cement pastes, J. Mater. Sci. 26 (1991) 349-353. doi:10.1007/BF00576526.

[37] S.J. Ford, J.D. Shane, T.O. Mason, Assignment of features in impedance spectra of the cementpaste/steel system, Cem. Concr. Res. 28 (1998) 1737-1751. doi:10.1016/S0008-8846(98)001562.

[38] R.T. Coverdale, B.J. Christensen, H.M. Jennings, T.O. Mason, D.P. Bentz, E.J. Garboczi, Interpretation of impedance spectroscopy of cement paste via computer modelling, J. Mater. Sci. 30 (1995) 712-719. doi:10.1007/BF00356331.

[39] J.M. Torrents, T.O. Mason, E.J. Garboczi, Impedance spectra of fiber-reinforced cement-based composites: a modeling approach, Cem. Concr. Res. 30 (2000) 585-592. doi:10.1016/S00088846(00)00211-8.

[40] J.M. Torrents, T.O. Mason, A. Peled, S.P. Shah, E.J. Garboczi, Analysis of the impedance spectra of short conductive fiber-reinforced composites, J. Mater. Sci. 36 (2001) 4003-4012.

[41] A.D. Hixson, L.Y. Woo, M.A. Campo, T.O. Mason, E.J. Garboczi, Intrinsic Conductivity of 
Short Conductive Fibers in Composites by Impedance Spectroscopy, J. Electroceramics. 7 (2001) 189-195.

[42] T.O. Mason, M.A. Campo, A.D. Hixson, L.Y. Woo, Impedance spectroscopy of fiber-reinforced cement composites, Cem. Concr. Compos. 24 (2002) 457-465. doi:10.1016/S09589465(01)00077-4.

[43] A.D. Hixson, L.Y. Woo, M.A. Campo, T.O. Mason, The origin of nonlinear current-voltage behavior in fiber-reinforced cement composites, Cem. Concr. Res. 33 (2003) 835-840. doi:10.1016/S0008-8846(02)01062-1.

[44] B. Suryanto, W.J. McCarter, G. Starrs, G.V. Ludford-Jones, Electrochemical immittance spectroscopy applied to a hybrid PVA/steel fiber engineered cementitious composite, Mater. Des. 105 (2016) 179-189. doi:10.1016/j.matdes.2016.05.037.

[45] D.D.L. Chung, Electrically conductive cement-based materials, Adv. Cem. Res. 16 (2004) 167 176. doi:10.1680/adcr.2004.16.4.167.

[46] EN 196-1:2016 Methods of testing cement. Determination of strength, (2016).

[47] W.J. McCarter, G. Starrs, T.. Chrisp, Electrical monitoring methods in cement science, in: J. Bensted, P. Barnes (Eds.), Struct. Perform. Cem. Second Ed., 2nd Editio, 2001: pp. 442-456.

[48] L.Y. Woo, S. Wansom, N. Ozyurt, B. Mu, S.P. Shah, T.O. Mason, Characterizing fiber dispersion in cement composites using AC-Impedance Spectroscopy, Cem. Concr. Compos. 27 (2005) 627-636. doi:10.1016/j.cemconcomp.2004.06.003.

[49] H.W. Whittington, J. McCarter, M.C. Forde, The conduction of electricity through concrete, Mag. Concr. Res. 33 (1981) 48-60. doi:10.1680/macr.1981.33.114.48.

[50] P. Gu, P. Xie, J.J. Beaudoin, R. Brousseau, A.C. impedance spectroscopy (I): A new equivalent circuit model for hydrated portland cement paste, Cem. Concr. Res. 22 (1992) 833-840. doi:10.1016/0008-8846(92)90107-7.

[51] D.E. Macphee, D.C. Sinclair, S.L. Cormack, Development of an Equivalent Circuit Model for Cement Pastes from Microstructural Considerations, J. Am. Ceram. Soc. 80 (1997) 2876-2884. doi:10.1111/j.1151-2916.1997.tb03206.x.

[52] G. Song, Equivalent circuit model for AC electrochemical impedance spectroscopy of concrete, Cem. Concr. Res. 30 (2000) 1723-1730. doi:10.1016/S0008-8846(00)00400-2.

[53] L.Y. Woo, S. Wansom, A.D. Hixson, M.A. Campo, T.O. Mason, A universal equivalent circuit model for the impedance response of composites, J. Mater. Sci. 38 (2003) 2265-2270.

[54] M. Keddam, H. Takenouti, X.R. Nóvoa, M.C. Andrade, C. Alonso, Impedance measurements on cement paste, Cem. Concr. Res. 27 (1997) 1191-1201. doi:10.1016/S0008-8846(97)001178 .

[55] NT Build 492, North Test BUILD 492 - Chloride Migration Coefficient from Non-Steady-State Migration Experiments, 1999.

[56] ASTM C1202 - 12, Standard Test Method for Electrical Indication of Concrete's Ability to Resist Chloride Ion Penetration, ASTM Int. (2012) 1-8. doi:10.1520/C1202-12.2.

[57] E. Barsoukov, J.R. Macdonald, Impedance Spectroscopy: Theory, Experiment, and Applications, John Wiley \& Sons, Inc., Hoboken, NJ, USA, 2005. doi:10.1002/0471716243.

[58] F. Kremer, A. Schönhals, Broadband Dielectric Measurements Techniques (10e-6 Hz to 10e12 $\mathrm{Hz}$ ), in: Broadband Dielectr. Spectrosc., Springer, 2002: pp. 34-57.

[59] R.T. Coverdale, B.J. Christensen, T.O. Mason, H.M. Jennings, E.J. Garboczi, Interpretation of 
the impedance spectroscopy of cement paste via computer modelling, J. Mater. Sci. 29 (1994) 4984-4992. doi:10.1007/BF01151088.

[60] L. Bertolini, B. Elsener, P. Pedeferri, R. Polder, Corrosion of Steel in Concrete. Prevention, Diagnosis, Repair., Wiley-VCH Verlag GmbH \& Co. KGaA, Weinheim, Germany, 2004.

[61] J.M. Østvik, C.K. Larsen, Ø. Vennesland, E.J. Sellevold, M.C. Andrade, Electrical resistivity of concrete Part I: Frequency dependence at various moisture contents and temperatures, in: 2nd Int. Symp. Adv. Concr. through Sci. Eng., 11-13 Septembe, Quebec City, Canada, 2006.

[62] J.D. Eshelby, The Determination of the Elastic Field of an Ellipsoidal Inclusion, and Related Problems, Proc. R. Soc. A Math. Phys. Eng. Sci. 241 (1957) 376-396. doi:10.1098/rspa.1957.0133.

[63] H. Hatta, M. Taya, Effective thermal conductivity of a misoriented short fiber composite, J. Appl. Phys. 58 (1985) 2478-2486. doi:10.1063/1.335924.

[64] B.S. Mitchell, An Introduction to Materials Engineering and Science, John Wiley \& Sons, Inc., Hoboken, NJ, USA, 2003. doi:10.1002/0471473359.

[65] F.J. Baeza, O. Galao, E. Zornoza, P. Garcés, Effect of aspect ratio on strain sensing capacity of carbon fiber reinforced cement composites, Mater. Des. 51 (2013) 1085-1094. doi:10.1016/j.matdes.2013.05.010. 